\title{
Cloud characteristics, thermodynamic controls and radiative impacts during the Observations and Modeling of the Green Ocean Amazon (GoAmazon2014/5) experiment
}

\author{
Scott E. Giangrande ${ }^{1}$, Zhe Feng ${ }^{2}$, Michael P. Jensen ${ }^{1}$, Jennifer M. Comstock ${ }^{1}$, Karen L. Johnson ${ }^{1}$, Tami Toto ${ }^{1}$, \\ Meng Wang ${ }^{1}$, Casey Burleyson ${ }^{2}$, Nitin Bharadwaj ${ }^{2}$, Fan $\mathrm{Mei}^{2}$, Luiz A. T. Machado ${ }^{3}$, Antonio O. Manzi ${ }^{4}$, \\ Shaocheng Xie ${ }^{5}$, Shuaiqi Tang ${ }^{5}$, Maria Assuncao F. Silva Dias ${ }^{6}$, Rodrigo A. F de Souza ${ }^{7}$, Courtney Schumacher ${ }^{8}$, and \\ Scot T. Martin ${ }^{9}$ \\ ${ }^{1}$ Environmental and Climate Sciences Department, Brookhaven National Laboratory, Upton, NY, USA \\ ${ }^{2}$ Pacific Northwest National Laboratory, Richland, WA, USA \\ ${ }^{3}$ National Institute for Space Research, São José dos Campos, Brazil \\ ${ }^{4}$ National Institute of Amazonian Research, Manaus, Amazonas, Brazil \\ ${ }^{5}$ Lawrence Livermore National Laboratory, Livermore, CA, USA \\ ${ }^{6}$ University of São Paulo, São Paulo, Department of Atmospheric Sciences, Brazil \\ ${ }^{7}$ State University of Amazonas (UEA), Meteorology, Manaus, Brazil \\ ${ }^{8}$ Texas A\&M University, College Station, Department of Atmospheric Sciences, TX, USA \\ ${ }^{9}$ Harvard University, Cambridge, School of Engineering and Applied Sciences and Department \\ of Earth and Planetary Sciences, MA, USA \\ Correspondence to: Scott E. Giangrande (sgrande@bnl.gov)
}

Received: 12 May 2017 - Discussion started: 24 May 2017

Revised: 30 August 2017 - Accepted: 11 September 2017 - Published: 6 December 2017

\begin{abstract}
Routine cloud, precipitation and thermodynamic observations collected by the Atmospheric Radiation Measurement (ARM) Mobile Facility (AMF) and Aerial Facility (AAF) during the 2-year US Department of Energy (DOE) ARM Observations and Modeling of the Green Ocean Amazon (GoAmazon2014/5) campaign are summarized. These observations quantify the diurnal to large-scale thermodynamic regime controls on the clouds and precipitation over the undersampled, climatically important Amazon basin region. The extended ground deployment of cloud-profiling instrumentation enabled a unique look at multiple cloud regimes at high temporal and vertical resolution. This longerterm ground deployment, coupled with two short-term aircraft intensive observing periods, allowed new opportunities to better characterize cloud and thermodynamic observational constraints as well as cloud radiative impacts for modeling efforts within typical Amazon "wet" and "dry" seasons.
\end{abstract}

\section{Introduction}

The simulation of clouds and the representation of cloud processes and associated feedbacks in global climate models (GCMs) remains the largest source of uncertainty in predictions of climate change (Klein and Del Genio, 2006; Del Genio, 2012). Collecting routine cloud observations to serve as constraints for the improvement of cloud parameterizations represents an ongoing challenge (e.g., Mather and Voyles, 2013), but one necessary to overcome deficiencies in GCM cloud characterizations. Compounding this challenge, cloud-climate feedbacks operate over extended spatiotemporal scales, while cloud behaviors vary significantly according to the regionally varying forcing conditions (e.g., Rossow et al., 2005). There is additional demand to observe and model cloud processes and feedbacks across many undersampled regions, including climatically important tropical locations where it is often difficult to deploy ground equipment.

As introduced by Martin et al. (2016, 2017), the Observations and Modeling of the Green Ocean Amazon (GoAma- 
zon2014/5) experiment was motivated by demands to gain a better understanding of aerosol, cloud and precipitation interactions on climate and the global circulation. The Amazon forest is the largest tropical rain forest on the planet, featuring prolific and diverse cloud conditions that span "wet" and "dry" precipitation regimes. These regimes and associated variations in cloud types, coverage and intensity from sub-daily to seasonal scales, are interconnected to large-scale shifts in the thermodynamic forcing and coupled local cloudscale feedbacks (e.g., Fu et al., 1999; Machado et al., 2004; $\mathrm{Li}$ and Fu, 2004; Fu and Li, 2004; Misra, 2008). The inability of GCMs to adequately represent clouds over such a complex and expansive tropical area sets apart GoAmazon2014/5 as an important asset for the improvement of GCM cloud parameterizations and simulations of possible climate change (e.g., Williams et al., 2002; Richter and Xie, 2008; Nobre et al., 2009; Yin et al., 2013).

One key component for cloud life cycle and process studies during GoAmazon2014/5 was the 2-year deployment of the Atmospheric Radiation Measurement (ARM; Stokes and Schwartz, 1994; Ackerman and Stokes, 2003) Mobile Facility (AMF; Miller et al., 2016) $70 \mathrm{~km}$ to the west of Manaus in central Amazonia, Brazil $\left(3^{\circ} 12^{\prime} 46.70^{\prime \prime} \mathrm{S}, 60^{\circ} 35^{\prime} 53.0^{\prime \prime} \mathrm{W}\right)$. This location was chosen to sample the extremes of the local pristine atmosphere, as well as the effects of the Manaus, Brazil, pollution plume. The AMF was equipped to capture a continuous record of column cloud and precipitation characteristics from multi-sensor profiling instrumentation, while routine surface meteorology and flux measurements along with balloon-borne radiosonde measurements provided information on the local thermodynamic state (e.g., Kollias et al., 2009; Xie et al., 2015; Tang et al., 2016). Deploying such an extended, comprehensive cloud instrumentation suite of this sort is unique to Amazon basin studies and rare within global climate-cloud interaction studies overall, particularly in the tropics. From this dataset, longer-term composites and statistical perspectives on diurnal to seasonal cloud variability (e.g., cloud development, morphological transitions, precipitation occurrence and radiative properties) are possible.

The long-term, ground-based measurements during GoAmazon2014/5 were complemented with aircraft-based measurements using the US Department of Energy (DOE) ARM Gulfstream-1 (G1) aircraft (ARM Areal Facility (AAF), e.g., Schmid et al., 2016). The G1 was equipped with instruments for measuring clouds, aerosol, chemistry and atmospheric state (e.g., Martin et al., 2017), which provide additional aerosol and cloud microphysical information that is not readily measured at the surface. These data help with the interpretation of ground-based measurements, while the ground measurements assist when determining the representativeness of these aircraft data.

This GoAmazon2014/5 cloud overview serves as a focused cloud study to complement the campaign overview effort found in Martin et al. (2017) and is outlined as follows. Section 2 introduces the AMF instrumentation and methods used for cloud classification and composite cloud properties. A 2-year summary of the environmental conditions and cloud observations in terms of fractional cloud coverages is presented in Sect. 3. These observations are segregated according to cloud types associated with large-scale Amazon wet and dry precipitation regimes. Section 4 details the observations for individual cloud types and their relative impact on surface energy and fluxes. This analysis includes additional relationships between campaign aircraft in-cloud observations when available. A brief discussion and summary of the initial cloud insights from the GoAmazon2014/5 deployment are found in Sect. 5.1

\section{ARM mobile facility cloud observations}

The AMF was deployed in Manacapuru, to the west of Manaus in central Amazonia, Brazil (Fig. 1, herein "T3" site; Martin et al., 2017). Cloud observations were obtained near continuously over a period from February 2014 to December 2015. The Amazon region surrounding T3 is often identified as the "green ocean", in reference to its unique atmospheric conditions that exhibit tropical and continental cloud characteristics (e.g., Williams et al., 2002). The T3 site is situated nearby the intersection of the large Amazon (Rio Solimões) and Rio Negro rivers (Fig. 1), a region of abundant moisture (humidity). As a consequence, T3 and the Manaus region may experience increased cloudiness and unique precipitation cycles as compared to the conditions over the larger Amazon basin (e.g., Oliveira and Fitzjarrald, 1993; Silva Dias et al., 2004; Romatschke and Houze, 2010; Dos Santos et al., 2014). Collow and Miller (2016) recently showed that the presence of the nearby rivers contributed to spatial variability in the regional radiation budgets around the AMF site. Recent GoAmazon2014/5 work has found a robust relationship between column-integrated water vapor and precipitation over the Amazon (Schiro et al., 2016). Seasonal thermodynamical shifts, as well as additional large-scale sea breeze front-type intrusions into the basin (e.g., Cohen et al., 1995; Alcântara et al., 2011), promote additional cloud life cycle and diurnal cycle of precipitation variability (e.g., Burleyson et al., 2016; Saraiva et al., 2016). Readers are also directed to complementary GoAmazon2014/5 studies on the largescale environmental controls on clouds, cloud transitions and precipitation found in Ghate and Kollias (2016), Tang et al. (2016), Collow et al. (2016) and Zhuang et al. (2017). Our analysis focuses on the $\mathrm{T} 3$ site that captured a wide range of shallow to deep cloud conditions, sampled and categorized using multi-sensor AMF methods detailed in this section. Larger-scale forcing datasets (including advective tendencies and vertical velocities) over this region were also supported by domain precipitation estimates available from the System for the Protection of Amazonia (SIPAM) S-band radar operated at the Ponta Pelada airport (T1; Fig. 1). 
Table 1. Cloud-type definitions based on cloud boundaries and thickness. Definitions are slightly modified from Burleyson et al. (2015) (their Table 2) and McFarlane et al. (2013) (their Table 3).

\begin{tabular}{lrrr}
\hline Cloud type & Cloud-base height & Cloud-top height & Cloud thickness \\
\hline Shallow & $<3 \mathrm{~km}$ & $<3 \mathrm{~km}$ & No restriction \\
Congestus & $<3 \mathrm{~km}$ & $3-8 \mathrm{~km}$ & $\geq 1.5 \mathrm{~km}$ \\
Deep convection & $<3 \mathrm{~km}$ & $>8 \mathrm{~km}$ & $\geq 5 \mathrm{~km}$ \\
Altocumulus & $3-8 \mathrm{~km}$ & $3-8 \mathrm{~km}$ & $<1.5 \mathrm{~km}$ \\
Altostratus & $3-8 \mathrm{~km}$ & $3-8 \mathrm{~km}$ & $\geq 1.5 \mathrm{~km}$ \\
Cirrostratus/anvil & $3-8 \mathrm{~km}$ & $>8 \mathrm{~km}$ & $\geq 1.5 \mathrm{~km}$ \\
Cirrus & $>8 \mathrm{~km}$ & $>8 \mathrm{~km}$ & No restriction \\
\hline
\end{tabular}

Table 2. Frequencies of cloud occurrence in the column and associated conditional shortwave (SW) transmissivity (SW trans), conditional SW cloud radiative effect (SW CRE) and conditional longwave (LW) cloud radiative effect (LW CRE) for each cloud type. All values are averaged across the diurnal cycle. For SW CRE, only daytime hours are included. SW transmissivity values in parentheses are standard deviations (SDs).

\begin{tabular}{|c|c|c|c|c|c|c|}
\hline & & $\begin{array}{r}\text { Mean } \\
\text { frequency } \\
\text { of cloud } \\
(\%)\end{array}$ & $\begin{array}{r}\text { Mean frequency } \\
\text { as the lowest } \\
\text { cloud in } \\
\text { column }(\%)\end{array}$ & $\begin{array}{r}\text { SW trans } \\
(\mathrm{SD})\end{array}$ & $\begin{array}{l}\text { SW CRE } \\
\left(\mathrm{Wm}^{-2}\right)\end{array}$ & $\begin{array}{l}\text { LW CRE } \\
\left(\mathrm{Wm}^{-2}\right)\end{array}$ \\
\hline \multirow[t]{3}{*}{ Low } & All data & 22.1 & 22.1 & $0.64(0.28)$ & -177.5 & 17.7 \\
\hline & Wet seasons & 27.9 & 27.9 & $0.60(0.28)$ & -210.8 & 18.3 \\
\hline & Dry seasons & 16.8 & 16.8 & $0.71(0.27)$ & -132.5 & 15.1 \\
\hline \multirow[t]{3}{*}{ Congestus } & All data & 5.7 & 4.8 & $0.36(0.25)$ & -326.6 & 26.3 \\
\hline & Wet seasons & 8.9 & 7.5 & $0.34(0.23)$ & -346.3 & 25.5 \\
\hline & Dry seasons & 2.8 & 2.4 & $0.40(0.29)$ & -284.1 & 26.7 \\
\hline \multirow[t]{3}{*}{ Deep Conv. } & All data & 5.2 & 4.9 & $0.17(0.15)$ & -425.9 & 28.4 \\
\hline & Wet seasons & 9.0 & 8.4 & $0.18(0.15)$ & -429.3 & 27.0 \\
\hline & Dry seasons & 1.5 & 1.4 & $0.17(0.16)$ & -487.6 & 33.4 \\
\hline \multirow[t]{3}{*}{ Altocumulus } & All data & 19.6 & 13.6 & $0.73(0.30)$ & -131.8 & 10.2 \\
\hline & Wet seasons & 25.3 & 16.0 & $0.69(0.30)$ & -153.4 & 10.1 \\
\hline & Dry seasons & 14.9 & 11.6 & $0.79(0.29)$ & -102.3 & 8.5 \\
\hline \multirow[t]{3}{*}{ Altostratus } & All data & 1.9 & 1.0 & $0.52(0.29)$ & -233.3 & 15.9 \\
\hline & Wet seasons & 3.1 & 1.5 & $0.47(0.25)$ & -252.0 & 14.9 \\
\hline & Dry seasons & 0.8 & 0.4 & $0.57(0.32)$ & -161.1 & 16.7 \\
\hline \multirow[t]{3}{*}{ Cirrostratus } & All data & 7.6 & 4.2 & $0.50(0.31)$ & -243.8 & 11.4 \\
\hline & Wet seasons & 10.3 & 4.9 & $0.44(0.25)$ & -296.9 & 12.4 \\
\hline & Dry seasons & 4.2 & 2.6 & $0.61(0.36)$ & -222.8 & 10.1 \\
\hline \multirow[t]{3}{*}{ Cirrus } & All data & 29.7 & 17.2 & $0.79(0.26)$ & -100.3 & 3.8 \\
\hline & Wet seasons & 30.4 & 13.4 & $0.74(0.28)$ & -121.2 & 3.8 \\
\hline & Dry seasons & 24.9 & 18.0 & $0.85(0.23)$ & -81.6 & 2.3 \\
\hline
\end{tabular}

We characterize cloud and precipitation properties according to seasonal and diurnal cycles that separate the observed cloud characteristics between relatively "wet" (herein, December through April) and "dry" (herein, June through September) season behaviors. While transitional months (May, October and November) are not an emphasis of this study, these months contain several intense (e.g., updraft strength and rainfall rates) deep convective events in the GoAmazon2014/5 record. Thermodynamic profiling (ra- diosonde) and environmental forcing datasets as sampled over the T3 location are summarized in Sect. 2.1. To better anchor cloud properties within these wet and dry regimes, aircraft flight operations during GoAmazon2014/5 prioritized two intensive operating periods (IOPs: 1 February31 March 2014 and 15 August-15 October 2014) as introduced in Sect. 2.2.

Traditionally, cloud fraction (CF) observations are of high interest within the GCM community and for high-resolution 


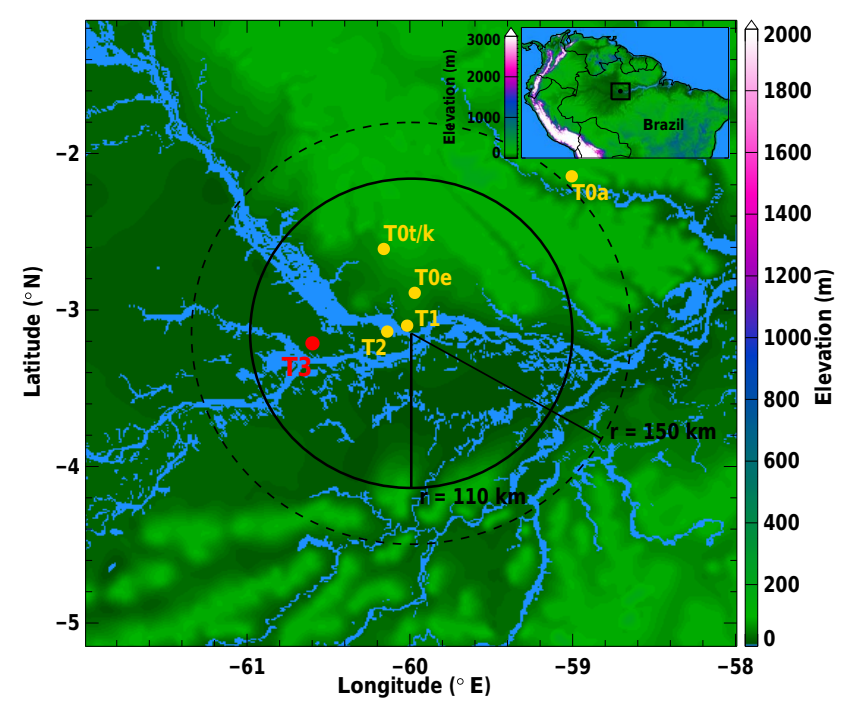

Figure 1. Location of the GoAmazon2014/5 key deployment sites and associated terrain elevation (shaded). The primary ARM AMF facilities were located at the T3 location. Range rings indicate distances from the SIPAM radar location near T1. The $110 \mathrm{~km}$ range ring is the range associated with the ARM continuous forcing dataset domain.

climate model evaluation (e.g., Bedacht et al., 2007; Wilkinson et al., 2008). Cloud breakdowns within our study focus on the diurnal to seasonal controls on these CF estimates. This is accomplished by segregating CF properties according to the results of a cloud-type classification algorithm. The multi-sensor approach and cloud classification methods are described in Sect. 2.3 and 2.4. Note that the interpretation of CF estimates and 1-D column CF estimate representativeness is often nontrivial (e.g., Wu et al., 2014). This study defines CF as the fraction of observations (heightresolved or over the entire column) within an hour for which the combined profiling sensors identify clouds overhead. In this study, cloud fraction and cloud frequency are used interchangeably.

\subsection{Radiosonde, surface meteorology and large-scale forcing dataset overview}

During the campaign, radiosondes were launched over T3 at regular $6 \mathrm{~h}$ intervals $(01: 30,07: 30,13: 30$ and 19:30 LT, Vaisala RS-92 radiosondes; ARM, 1993). For the IOPs, one additional radiosonde was launched at 10:30 LT to enhance diurnal coverage. Basic thermodynamic processing was performed following Jensen et al. (2015) to estimate convective forcing parameters such as the lifting condensation level (LCL), mixed-layer height (MLH), convective available potential energy (CAPE) and convective inhibition (CIN). For each of these parameters, surface parcels are defined by the level of the maximum virtual temperature in the lowest kilometer. This represents the most buoyant parcel in the bound- ary layer and maximizes the calculated CAPE (thus, our reported values are comparable to "most unstable" CAPE or MUCAPE). The MLH is calculated using the definition of Liu and Lang (2010) that determines the MLH from a combination of the gradient of potential temperature and the vertical wind shear using criteria based on the stability of the boundary layer and the presence of a low-level jet. Surface radiative flux estimates for this study follow the radiative flux analysis methods of Long and Ackerman (2000) and Long and Turner (2008). The clear-sky radiative flux estimates are produced by employing an empirical function fitting approach during observed clear-sky periods. The fitted coefficients from these clear-sky intervals are used to interpolate over cloudy periods, providing a continuous estimate of clear-sky irradiances and quality-controlled cloudysky fluxes. Detailed analyses of cloud radiative effects are located in Sect. 4.

Figure 2 presents the cumulative time series for the 2year GoAmazon2014/15 dataset in terms of average daily profile values for basic cloud, precipitation, thermodynamical and dynamical observations from multi-sensor ground instruments at the T3 site. These efforts complement previous papers on seasonal variability for cloud conditions over the larger Amazon basin (e.g., Machado et al., 2004). We observe clear shifts in several quantities associated with the Amazon wet and dry seasons. Our ranges for wet and dry season months, as well as the IOPs, are shown in Fig. 2 as a reference to the appropriateness for those windows compared to the larger-scale conditions. The more pronounced shifts during the wet season include increased CF in the mid-to-upper troposphere (between 3 and $10 \mathrm{~km}$; Fig. 2a), higher precipitation rates (over these daily integrations) and precipitable water (PW; Fig. 2b), as well as the buildup of relative humidity (RH) profiles through the middle levels (Fig. 2d). Previous studies suggest that $\mathrm{CAPE}, \mathrm{CIN}$ and zonal/meridional winds (Fig. 2c, e and f) from radiosondes may also illustrate large-scale thermodynamical changes and moisture transport associated with wet, dry and transitional periods (e.g., Li and $\mathrm{Fu}, 2004 ; \mathrm{Fu}$ and $\mathrm{Li}$, 2004). Radiosonde daily maximum values indicate only small seasonal changes in CAPE and CIN, although we observe that the transitional periods between the dry and wet seasons promote maximum relative CAPE trends coupled with relatively lower CIN and heightened moisture. These are the primary ingredients that promote more frequent and strong convection, provided convection can be triggered (e.g., Machado et al., 2004). Although areal coverage of deeper convection is generally the largest during the wet season, recent profiler-based studies suggest the strongest storms (in terms of upward vertical air motion) were often observed towards the end of the dry season and into the transitional period (e.g., Giangrande et al., 2016; Nunes et al., 2016).

The diurnal variation of atmospheric state is illustrated in Fig. 3 and shows the evolutions for the mean and standard deviation of (a) CAPE, (b) CIN, (c) LCL and (d) MLH 


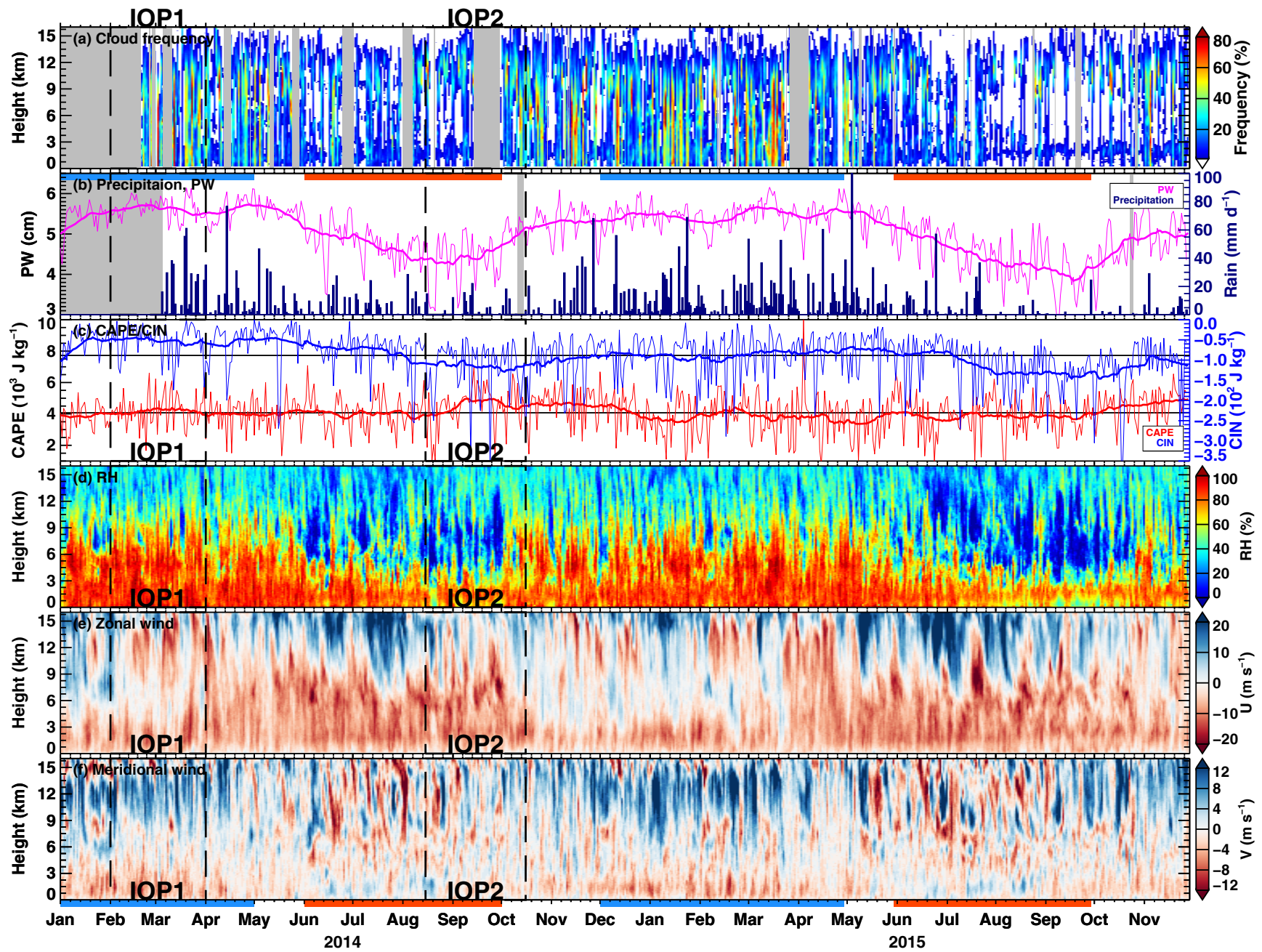

Figure 2. Time series of (a) cloud frequency from the merged WACR-ARSCL-RWP dataset, (b) column precipitable water (purple; thick line is the 30-day running mean) and surface precipitation (dark blue bars), sounding measurements of (c) daily maximum CAPE (red), daily minimum CIN (blue), two horizontal lines are their respective mean values, (d) relative humidity (with respect to liquid), (e) zonal wind and (f) meridional wind. The data shown are daily average values. Gray fillings in panels (a, b) are periods with missing cloud or precipitation data, respectively. "Wet" and "dry" seasons in this study are denoted with blue and orange bars in panels (b, f); IOP1 and IOP2 periods are denoted by the vertical dash lines.

separated into dry (red bars) and wet (blue bars) components (e.g., Betts et al., 2002). CAPE increases after sunrise, reaching a maximum near midday, whereas CIN is maximum (largest negative value) overnight and decreases during the day. These behaviors are consistent with development of convection breaking the capping inversion and consuming CAPE. Both CAPE and CIN show a stronger diurnal cycle during the dry season compared to the wet season. The mean LCL increases by approximately $600-800 \mathrm{~m}$ from sunrise to the afternoon with larger magnitudes and range during the dry season. The mean MLH also increases by approximately $1 \mathrm{~km}$ from sunrise through the afternoon during the wet season, while during the dry season the increase is about $1.5 \mathrm{~km}$. This increase in MLH is consistent with daytime solar heating. Separating the diurnal cycle into dry (red bars) and wet (blue bars) season components indicates slightly stronger diurnal cycle signatures in CAPE, increased CIN (e.g., larger negative values) and higher MLH for the dry season (similar to measurements obtained in the southwest Amazon by Fisch et al., 2004), with a suppressed diurnal cycle in LCL height.

To better inform the observed cloud system variations over the ARM T3 site from the large-scale environmental condition perspective, Fig. 4 plots the diurnal cycle of the largescale vertical motion (omega), total advection of moisture and relative humidity. The total advection of moisture is the sum of the horizontal and the vertical advection:

q_adv_t $=-V_{h} \cdot \nabla_{h} q-\omega \frac{\partial q}{\partial p}$. 

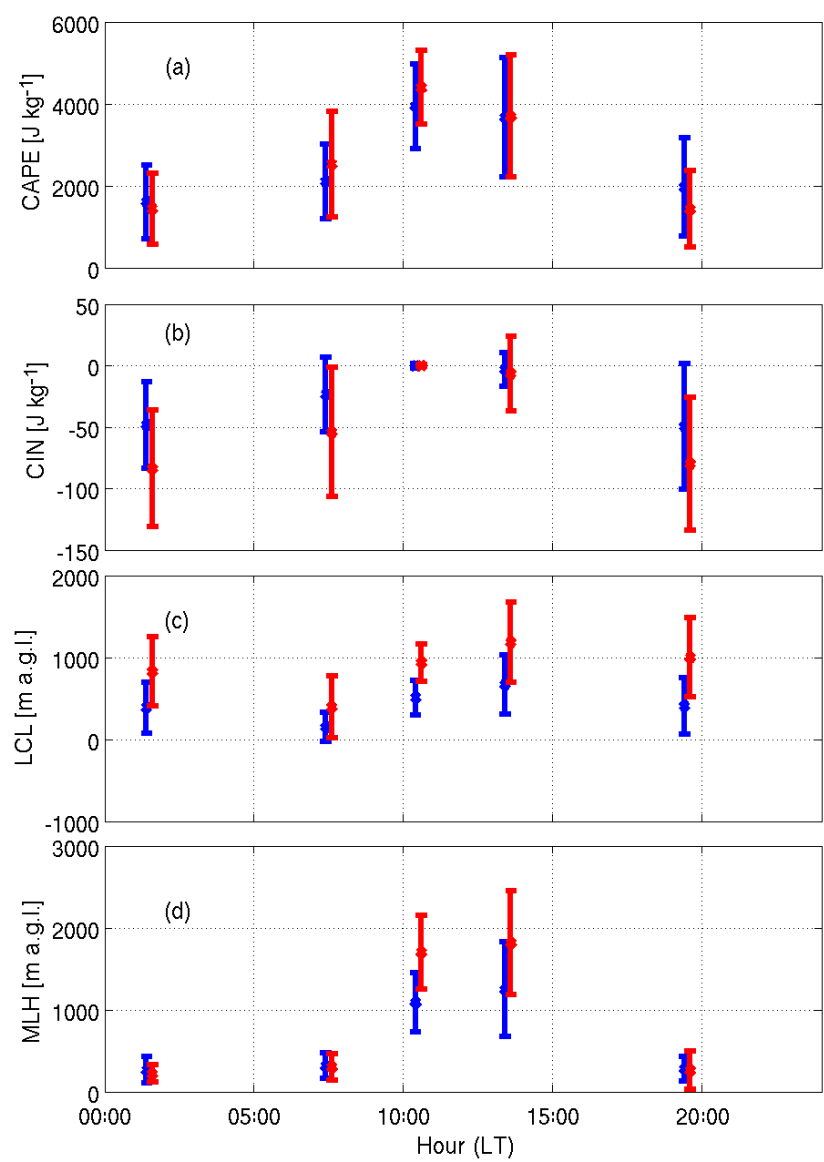

Figure 3. Diurnal cycles (mean and standard deviation) for radiosonde-based thermodynamic quantities of (a) CAPE, (b) CIN, (c) LCL height and (d) MLH for wet (blue) and dry (red) season breakdowns.

The total advection can be interpreted as 3-D moisture convergence. For the GoAmazon2014/5 period, the vertical component dominated the total moisture advection (not shown). These large-scale fields are derived from the ECMWF analysis outputs over the entire field campaign using a constrained variational analysis method of Zhang and Lin (1997). The upper-level state variables (wind, temperature, moisture) from ECMWF are adjusted to conserve column-integrated mass, moisture and energy. Surface rainfall rate from the SIPAM radar is used as a major constraint. Additional details on these large-scale fields for the GoAmazon2014/5 deployment can be found in Tang et al. (2016). This variational analysis is performed at 3-hourly intervals at $25 \mathrm{hPa}$ vertical resolution over a domain of about $110 \mathrm{~km}$ in radius, with the center located at the T1 site (Fig. 1).

The omega field shows strong upward air motion in the middle and upper troposphere during the mid-to-late afternoon (Fig. 4a). The evening and early morning hours exhibit upward air motion confined below 3-4 km due to lower-level convergence and middle-level divergence (not shown), likely corresponding to the congestus clouds. Above that level, downward air motion is dominant. This downward motion is most pronounced between 06:00 and 09:00 LT. After sunrise, we observe low-level weak ascending motions and positive advection of moisture (Fig. 4d). Between 4 and $8 \mathrm{~km}$ in the RH field, we observe dry middle tropospheric conditions and relatively wetter conditions near the tropopause (Fig. 4g). Similar structures in all fields are found across wet and dry season breakdowns; however, middle- and upperlevel descending motions during the evening and early morning hours are much stronger during the dry season, suppressing convection during those hours. In addition, the ascending motion between noon and late afternoon is much weaker in the dry season compared to the wet season. The dry season also exhibits reduced low-level positive moisture advection and a much dryer lower and middle atmosphere.

\subsection{The AAF aircraft dataset}

The DOE AAF G1 aircraft participated in two IOPs that coincided with the AMF deployment. Airborne measurements were conducted during 22 February-23 March 2014 and 6 September-4 October 2014, representative of the wet and dry seasons, respectively. The G1 flight patterns were designed to sample shallow and growing cumulus convective clouds that formed downwind from Manaus to examine the evolution of urban pollution and its effect on cloud and precipitation properties (Martin et al., 2017). Typical flights consisted of a series of level legs flown just below cloud base, just above cloud base and higher in growing cumulus clouds, including legs over the T3 ground site. In total, 16 and 19 flights in warm cumulus clouds were included in the wet and dry seasons, respectively.

The G1 payload was designed to measure the full spectrum of aerosol size from 0.015 to $3 \mu \mathrm{m}$ and cloud particle sizes from $2 \mu \mathrm{m}$ to $1.92 \mathrm{~cm}$. For this study, three cloud particle distribution probes are combined to create the full dropsize distribution (DSD) depictions presented in Sect. 4. The Droplet Measurements Technologies (DMT) cloud droplet probe $(\mathrm{CDP} ; 2-50 \mu \mathrm{m})$ is combined with the Spec Inc. twodimensional stereo probe (2-DS; $10 \mu \mathrm{m}-3 \mathrm{~mm}$ ) between 20 and $50 \mu \mathrm{m}$ by averaging the overlapping bins. The Spec Inc. high-volume precipitation spectrometer (HVPS; $150 \mu \mathrm{m}-$ $1.92 \mathrm{~cm}$ ) is used for droplets larger than $500 \mu \mathrm{m}$. Cloud droplet distributions are combined by averaging the DSD for each instrument separately over these flight periods. This was done for in-cloud conditions only. DSDs from the CDP are used for drops smaller than $20 \mu \mathrm{m}$. The DSDs from the CDP and 2-DS are averaged between 20 and $50 \mu \mathrm{m}, 2$-DS DSDs are used between 50 and $500 \mu \mathrm{m}$, and HVPS DSDs are used for drops larger than $500 \mu \mathrm{m}$. The 2-DS probe occasionally contained artifacts known as "stuck bits", i.e., when a photodiode becomes continuously occulted due to optical contamination or electronic noise (Lawson et al., 2006). Each flight was visually inspected for artifacts, which were manually re- 
moved from the combined DSDs. Cloud condensation nuclei $(\mathrm{CCN})$ were measured with a dual-column system manufactured by DMT (operated with a constant pressure inlet at $600 \mathrm{mbar}$ ), and liquid water content (LWC) was measured using a multi-wire element probe (Science Engineering Associates (SEA) water content meter WCM-2000) with wire sizes the same as King and Johnson-Williams probes.

\subsection{Radar dataset and multi-sensor merging}

The $95 \mathrm{GHz}$ W-band ARM cloud radar (WACR) (e.g., ARM, 2005; Giangrande et al., 2012) is the primary profiling instrument to characterize the cloud conditions during GoAmazon2014/5. Cloud masking and designation products are performed using the multi-sensor WACR preprocessing approach following active remote sensing of clouds methodologies (ARSCL; Clothiaux et al., 2000; Kollias et al., 2005,2009 ) and additional quality-control refinements following Kollias et al. (2014). These retrievals merge observations from the WACR and a collocated laser ceilometer, micropulse lidar (MPL) and microwave radiometer (MWR) to better identify cloud boundaries in the vertical at high temporal $(\sim 10 \mathrm{~s})$ and vertical $(\sim 24 \mathrm{~m})$ resolution.

There are several limitations when designating cloud boundaries and hourly $\mathrm{CF}$ observations from vertically pointing cloud radars beyond the capabilities of single radar platforms or ARSCL methods (e.g., Lamer and Kollias, 2015; Oue et al., 2016). The primary limitation among these is that the WACR experiences attenuation in rain that manifests as erroneously low or missing cloud-top boundaries (e.g., Feng et al., 2009, 2014). To lessen these impacts within this Amazonian deployment that favors frequent precipitating cumulus, a collocated and well-calibrated $1290 \mathrm{MHz}$ ultra-high frequency (UHF) radar wind profiler (RWP; $8^{\circ}$ beamwidth, $200 \mathrm{~m}$ gate spacing, $6 \mathrm{~s}$ temporal resolution) was co-gridded to improve cloud coverage through deeper precipitating clouds (e.g., ARM, 2009; Giangrande et al., 2013, 2016). For this study, a modification to the ARSCL cloud boundary designation is produced by merging RWP profiles (operating in "precipitation" modes, as also described in Tridon et al. (2013) during precipitation intervals following similar ARSCL-type cloud profile processing (Feng et al., 2014). The substitution is accomplished using collocated surface rain gauge datasets to help define appropriate "precipitation periods". These are defined as continuous time periods when the surface rain rate from the gauge exceeds $1 \mathrm{~mm} \mathrm{~h}^{-1}$. During these intervals, if more than $10 \%$ of the derived WACR first echo-top heights associated with these precipitating clouds are found to be $500 \mathrm{~m}$ or more below the echo-top height as recorded by the RWP, a WACR attenuation flag is assigned and the RWP profiles and boundaries are inserted.

Figure 5 illustrates an example of the composite cloud designation for the 1 April 2014 event. Earlier during this event, both the WACR (Fig. 5a) and RWP (Fig. 5b) strug- gle to sample the thin and/or high cloud regions observed by ARSCL (Fig. 5c). CF estimates in these regions benefit from the additional ceilometer and MPL observations (not shown in Fig. 5) to detect clouds. Congestus clouds, including those that have cloud tops at $\sim 6 \mathrm{~km}$, are observed reasonably well by both radars. In these times, surface precipitation is limited (Fig. 5d). A deep convective cloud system passes over T3 between 15:00 and 19:00 UTC. Heavy precipitation (surface measured rain rate $>60 \mathrm{~mm} \mathrm{~h}^{-1}$ ) is associated with extinction of the WACR signal, whereas the RWP is able to reconstruct cloud boundaries up to $13 \mathrm{~km}$. Since the RWP is sensitive only to precipitation-sized particles, these methods will still underestimate the true cloud top. Additional precipitation periods are also identified by red bars on top of Fig. 5c, highlighting locations where the cloud boundary designation within precipitation is improved over traditional ARSCL methods.

\subsection{Cloud classification and radiative properties}

A simple cloud-type classification is performed on the cloud boundary and masking dataset from Sect. 2.3. This approach follows McFarlane et al. (2013) and Burleyson et al. (2015). These methods classify clouds into seven categories according to the height of the cloud boundaries and cloud thickness. The cloud categories include shallow, congestus, deep convection, altocumulus, altostratus, cirrostratus/anvil and cirrus (definitions summarized in Table 1). Figure $5 \mathrm{c}$ provides an example of the cloud classifications for 1 April 2014. Cloud classification is used to separate surface radiative properties among the different cloud types. To accomplish this, the nearest cloud profile is matched to the $1 \mathrm{~min}$ surface radiative flux data. As with Burleyson et al. (2015), the lowest cloud type present in the column during that time is used to designate the shortwave and longwave radiative flux measurements (Fig. 5e and f) for that cloud type.

\section{Profiling observations of clouds and precipitation during GoAmazon2014/5}

As highlighted in Fig. 2, thermodynamic and cloud properties from this 2-year Amazon dataset are diverse and sampled near continuously by the ARM instrumentation to provide unique constraints towards model improvement. First, T3 cloud observations will be summarized according to diurnal and seasonal breakdowns that follow from large-scale shifts between wet and dry Amazon precipitation regimes. Breakdowns of CF associated with each cloud category defined in the previous section are located in Table 2 (a variation of this Table is also found in Figs. 10 and 12). For composite CF summaries presented in this section, we capitalize on the high temporal and vertical resolution of the ARM instruments to partition $\mathrm{CF}$ according to hourly profile estimates. 

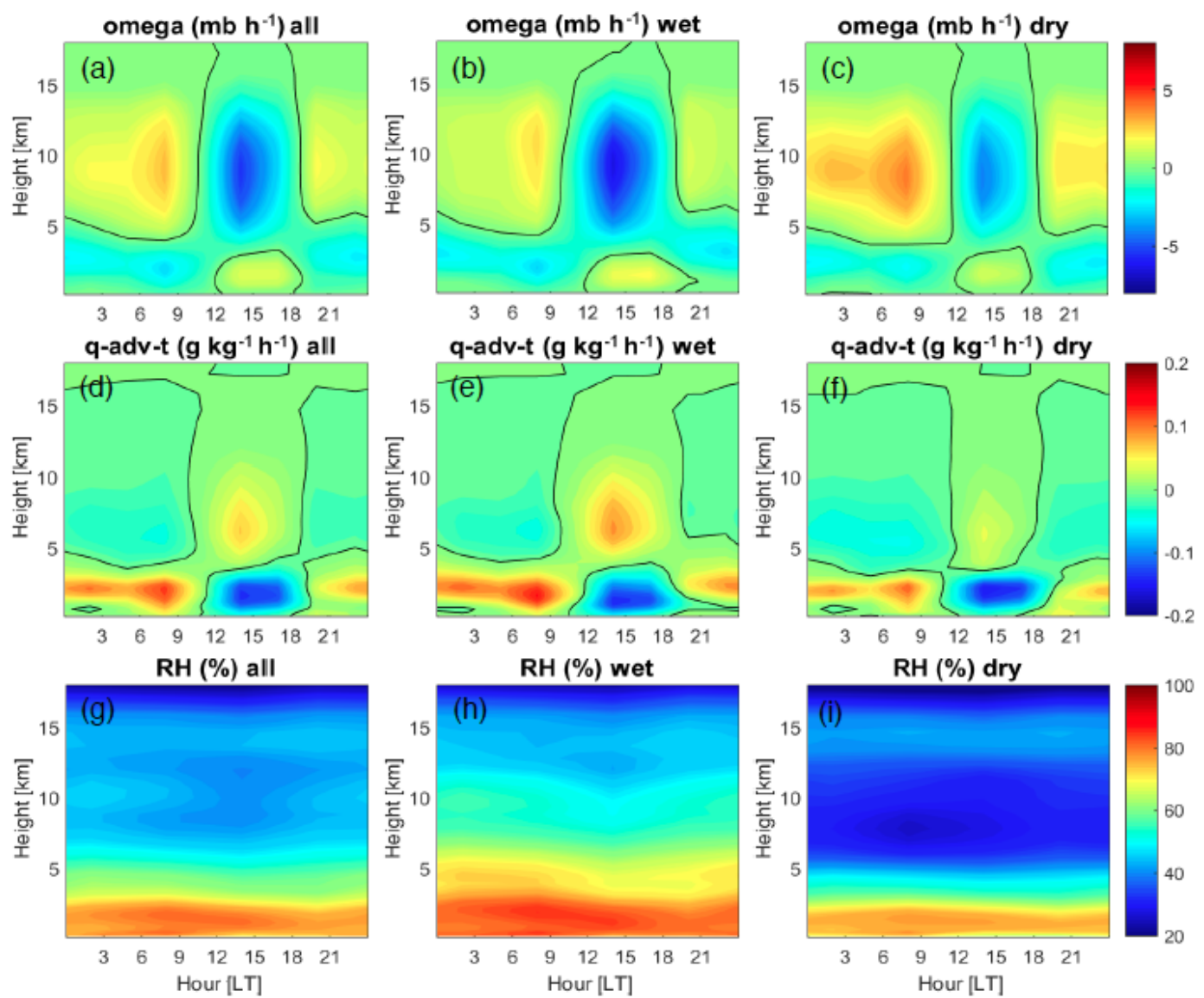

Figure 4. Diurnal cycles of omega, total advection of moisture and relative humidity (with respect to liquid) for the complete 2-year GoAmazon2014/15 campaign record (a, $\mathbf{d}, \mathbf{g})$, as well as wet season $(\mathbf{b}, \mathbf{e}, \mathbf{h})$ and dry season $(\mathbf{c}, \mathbf{f}, \mathbf{i})$ breakdowns.

Measurable precipitation ( $>1 \mathrm{~mm}$, daily) was frequent over the T3 site during the campaign according to surface rain gauge observations (as highlighted in Fig. 2b). In this dataset, 216 days recorded measurable precipitation from multiple ARM gauge and radar sensors, with 80 additional days recording light/trace precipitation $(<1 \mathrm{~mm})$. The total campaign precipitation over T3 was approximately $3000 \mathrm{~mm}$. This total T3 accumulation is representative of the regional SIPAM estimates reported in Zhuang et al. (2017), accounting for uncertainty in radar-based rainfall estimates, dataset gaps and discrepancies between point and spatial rainfall estimates. However, this total campaign precipitation may be below normal due to a late onset of the 20142015 rainy season and other factors (e.g., Fig. 4 of Marengo et al., 2017, $\sim 2300 \mathrm{~mm} \mathrm{yr}^{-1}$ ). Using collocated RWP echo classification methodologies when available (as described by Giangrande et al., 2016), it was possible to designate the fractional precipitation associated with convective and stratiform regimes. For this dataset, $\sim 76 \%$ of the accumulated precipitation was associated with convective precipitation. For this definition, we note that "deep convective" cloud regimes from our cloud classification are associated with both con- vective precipitation in the convective cores that pass over the site, as well as stratiform precipitation in the case of trailing widespread precipitation regions behind the convective lines and mesoscale convective systems (MCSs, e.g., Houze et al. (2015). Additional details on diurnal and regime breakdowns follow in the subsequent sections.

\subsection{Cloud and precipitation diurnal cycles}

Figure 6 shows diurnal CF profile breakdowns for each cloud category. The "cirrus" and "shallow" cloud categories are combined into a single panel since these cloud definitions do not overlap in altitude. Seasonal variations in the diurnal CF by cloud category are described in the next section. Figure $6 \mathrm{a}$ indicates that cirrus clouds are the most commonly observed clouds during the afternoon and overnight hours, whereas shallow cloud observations dominate the early morning hours after sunrise into the mid-afternoon. Combining Fig. 6a with summary cloud occurrence values in Table 2, shallow cumulus clouds in the Amazon are observed with relatively high frequency throughout most of the day $(\sim 22 \%)$. Shallow clouds in the early morning align with low-level weak ascending air motions (Fig. 4a) and the posi- 


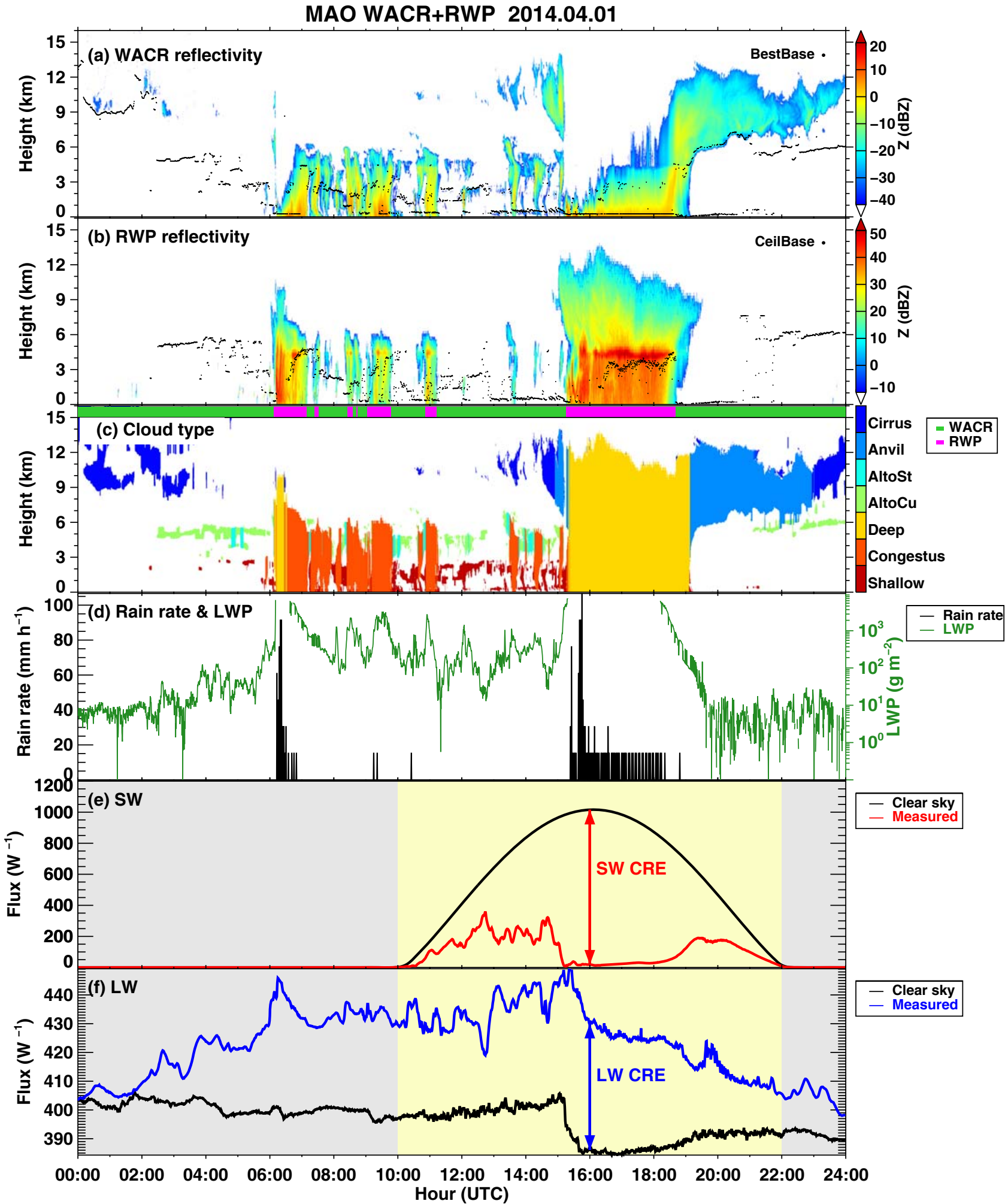

Figure 5. Example from the merged WACR-ARSCL-RWP dataset for a 1 April 2014 event: (a) WACR reflectivity, (b) RWP reflectivity, (c) cloud-type classification, (d) tipping bucket rain rate (black, 5 min increments) and MWR retrieved liquid water path (green), (e) downward shortwave flux and (f) downward longwave flux. The black dots in panels (a, b) reflect a best estimate cloud-base height and ceilometer cloud-base height from the WACR-ARSCL dataset. Magenta bars above panel (c) show periods when RWP data were used to replace WACR data (green bars). The black lines in panels $(\mathbf{e}, \mathbf{f})$ reflect clear-sky flux estimates from the radiative flux analysis product. The differences between clear-sky estimated fluxes and measured fluxes (denoted between the arrows in panels (e, f)) are defined as cloud radiative effects. 
(a) Shallow/cirrus

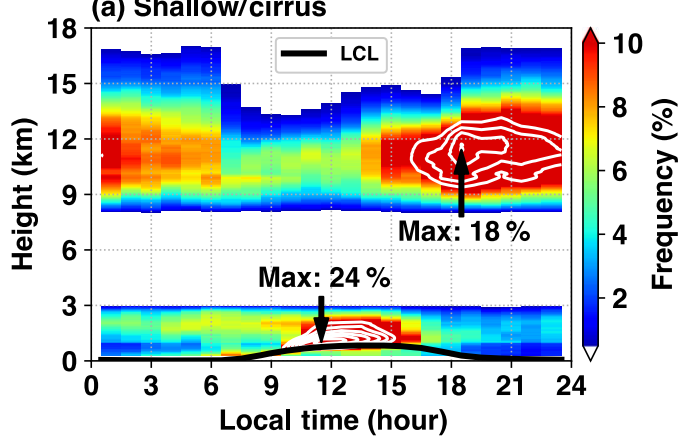

(c) Congestus

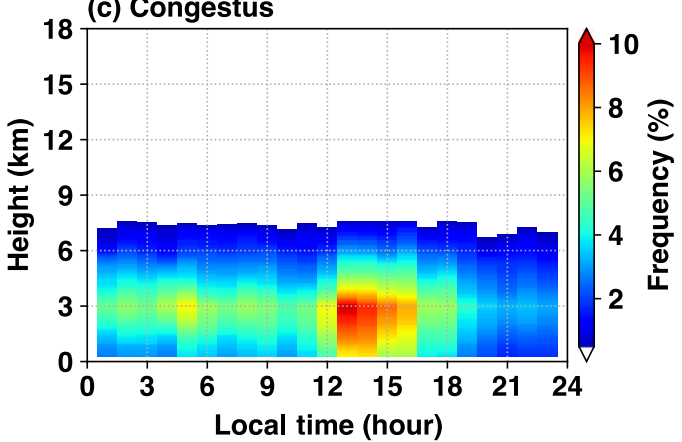

(e) Altocumulus

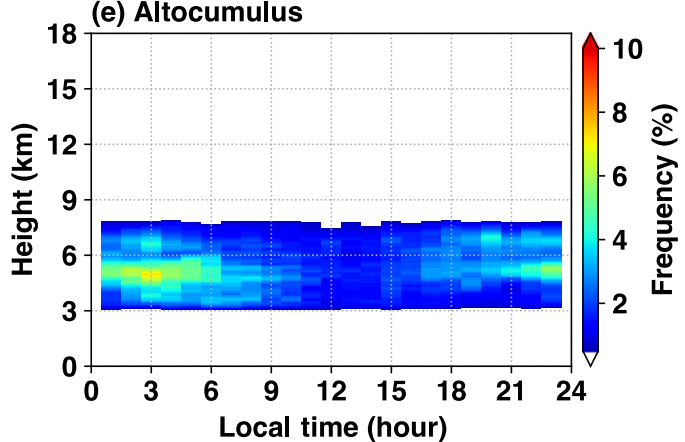

(b) Cirrostratus

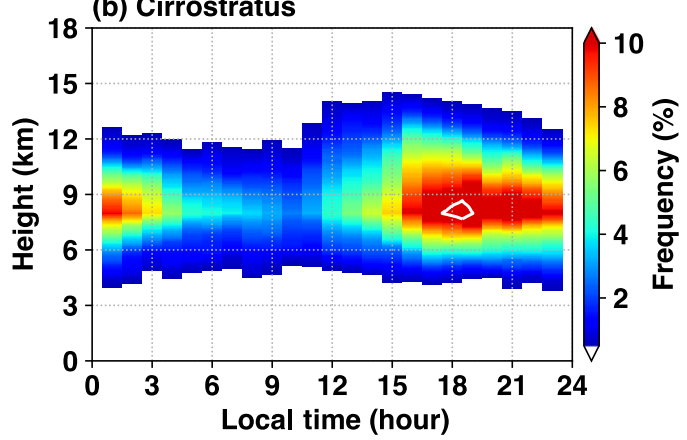

(d) Deep conv
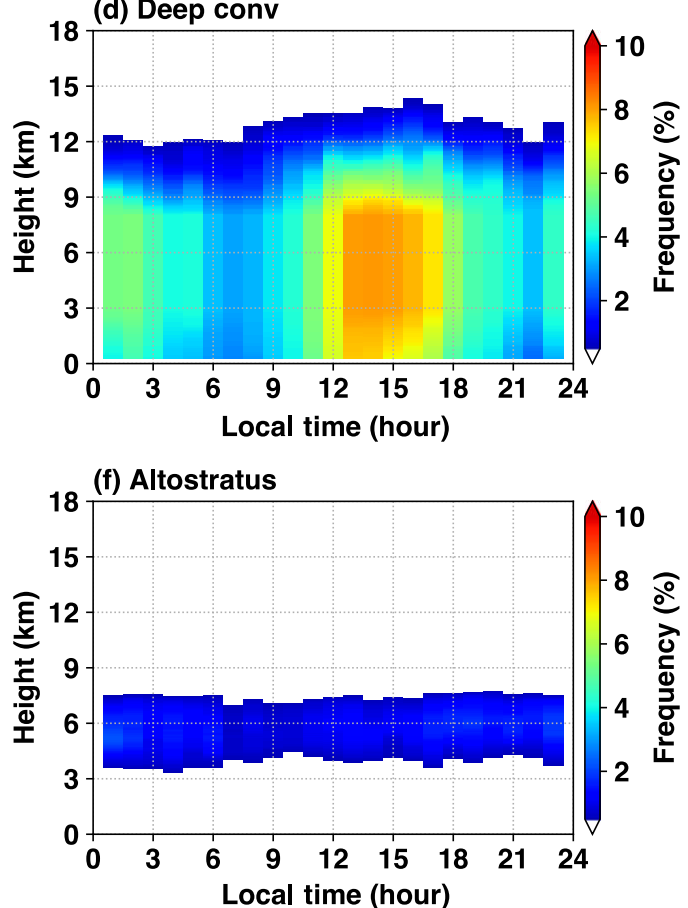

Figure 6. Composite diurnal cycle cloud fraction profiles segregated according to each of the seven cloud classification categories. White contours start at $10 \%$ and increments at $2 \%$. Maximum cloud fraction values for shallow and cirrus clouds are marked in panel (a). The black line in panel (a) plots the averaged LCL height estimated using surface measurements.

tive advection of moisture (Fig. 4d). The most common cirrus cloud locations correspond to relatively high $\mathrm{RH}$ regions in the upper atmosphere seen in Fig. $4 \mathrm{~g}$, where the air is close to saturation with respect to ice (not shown).

Congestus (Fig. 6c) and deep convective (Fig. 6d) clouds are prominent starting at noon into the late afternoon, with peak CF coverage $1-2 \mathrm{~h}$ after local noon. Deeper clouds that include MCS passages (identifiable using SIPAM observations) appear to maintain higher CFs into the overnight hours (associated with trailing stratiform regions). Integrated column behaviors are similar to those found from satellite over Manaus from Machado et al. (2004); specifically, cloud coverage is high throughout the day, peaking after local noon and associated with increased cirrus (Fig. 6a), cirrostratus (Fig. 6b) and deeper convective clouds (Fig. 6d). The T3 lo- cation exhibits a pronounced diurnal cycle associated with deeper convection (as also in Saraiva et al., 2016). This pronounced behavior is further representative of the fortuitous placement for the T3 AMF site, wherein daily cloud life cycles also phase well with propagating sea breeze intrusions over this portion of the Amazon basin (Burleyson et al., 2016). Primary diurnal peak behaviors of these clouds (enhanced afternoon convection and reduced overnight convective development) are associated with mid- and upper-level upward motion in the afternoon and downward air motion from night to the early morning (Fig. 4a).

Congestus and altocumulus exhibit weak peaks in the predawn hours (around 05:00LT). This is observed primarily as a wet season congestus behavior, possibly comparable to suggestions in previous Manaus diurnal rainfall ef- 

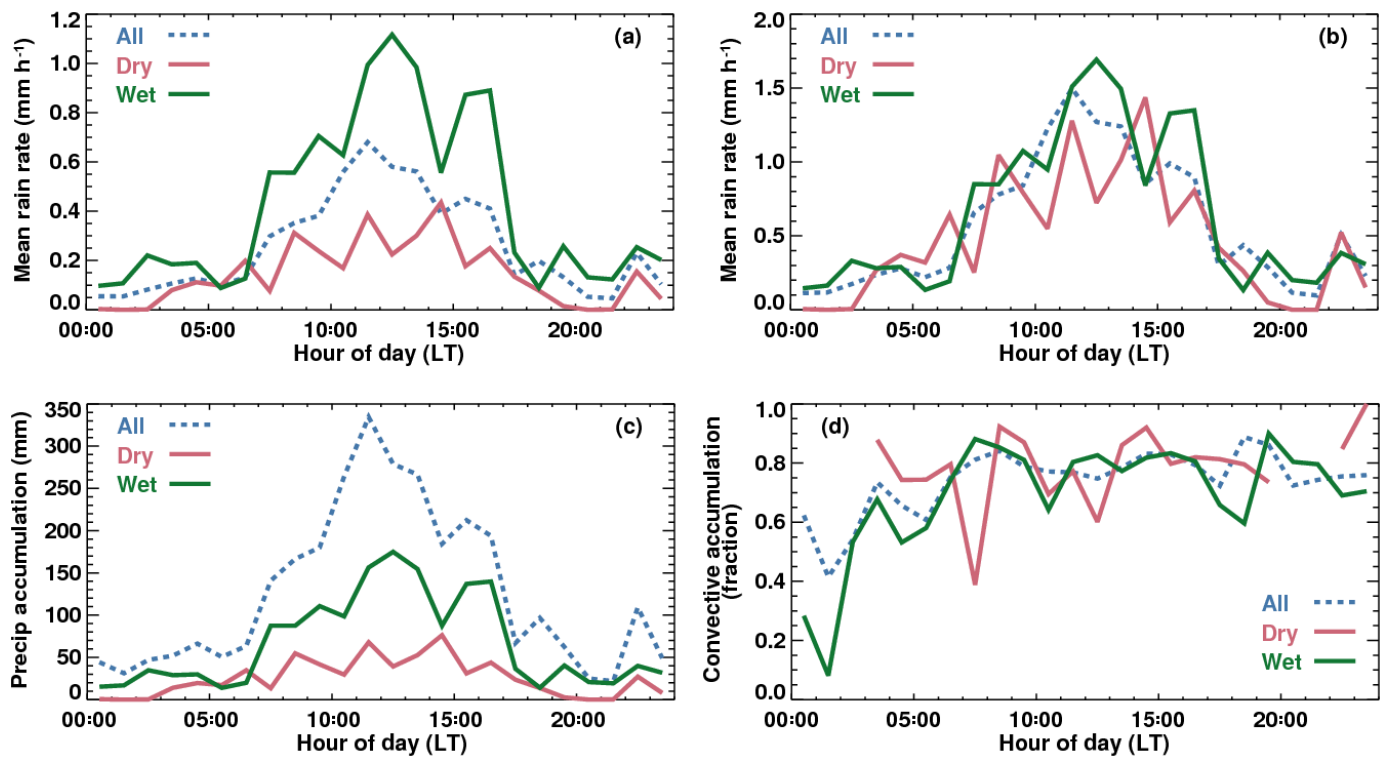

Figure 7. (a) Mean daily precipitation rate $\left(\mathrm{mm} \mathrm{h}^{-1}\right)$ for all days and (b) for only the precipitating days during the campaign $(>1 \mathrm{~mm})$. (c) The total accumulation in millimeters for the dataset and (d) the fractional convective accumulation as sampled by the rain gauges for the summary campaign and associated wet and dry season conditions.

forts (e.g., Machado et al., 2004). However, this contribution would typically be dwarfed when combining the rainfall contributions from other cloud types. We note that the nonprecipitating categories of altocumulus, altostratus and cirrostratus (Fig. 6b, e and f) share similar diurnal phasing with cirrus clouds. Cirrus and cirrostratus are more commonly observed than alto-cloud designations. However, we have not differentiated the contributions to cirrus $\mathrm{CF}$ estimates that reflect deep convective or anvil cloud components from other cirrus clouds. Overall, inspection of large-scale forcing fields supports the notion that the diurnal cycle of high-level clouds is not well associated with the diurnal cycle of the large-scale dynamics and thermodynamics. This may be indicative of the importance of clouds that originate from anvil remnants from deeper convective clouds or advect from elsewhere, in addition to the clouds that are forced and developed locally.

Figure 7 shows the diurnal cycle of precipitation properties at the T3 site as observed by the surface gauges collocated with RWP observations. These plots include wet, dry and transitional season contributions (although we do not isolate these transitional months). Average precipitation rates reflect the average across precipitating and non-precipitating days, peaking around 12:00 to 16:00 LT (Fig. 7a), consistent with the deep convective CF in Fig. 6d. Note that the mean rainfall rates including only days when precipitation is present (Fig. 7b) are more comparable between wet and dry season events, suggesting T3 results in Fig. 7a primarily reflect the additional frequency of convection during the wet season and not its relative intensity. The total rainfall accumulations for the various regimes are presented in Fig. 7c. Rainfall accumulations from Fig. 7c have also been sepa- rated into convective and stratiform types as designated by the RWP when available (Giangrande et al., 2016). For the composite campaign (dashed line in Fig. 7d), convective precipitation is dominant at $\sim 76 \%$ of the fractional accumulation $(\sim 2300 \mathrm{~mm})$ with a relatively flat contribution diurnally (especially during the dry season). Since this fractional accumulation is based on RWP estimates for convective fraction, it may tend to maximize convective precipitation fraction over traditional scanning radar-based retrievals (e.g., Steiner et al., 1995). This is because unlike basing these designations on radar reflectivity factor properties and buffering (proximity to convective cores based on intensity), profiler methods also distinguish columns with convective vertical air motions (including those from elevated, sloping updrafts that extend back into the transitional or trailing stratiform regions for MCSs), as well as congestus cloud precipitation (typically associated with clouds having echo tops exceeding $4 \mathrm{~km}$ ) as "convective" rainfall. Stratiform precipitation (approximately $700 \mathrm{~mm}$ for this dataset) is more frequent (in terms of accumulation) during the overnight hours (30-60\%) and is associated with the trailing precipitation regions from the convective systems. Again, based on our cloud classifications, deep convective clouds would contain convective and widespread stratiform precipitation components.

\subsection{Seasonal cloud regime cycles}

Figure 7 also plots the diurnal breakdowns for average rainfall rate and fractional convective accumulations during the two wet and dry seasons over T3. Our dataset contains 103 wet season days responsible for approximately $1600 \mathrm{~mm}$ of 
precipitation and 52 dry season days responsible for approximately $600 \mathrm{~mm}$ of precipitation. The wet season months are associated with a factor of 2 increase in mean rainfall rates, but even larger increases occur during daytime hours with much smaller changes during the late evening and early morning (Fig. 7a). However, relative to those days having precipitation (Fig. 7b), the differences in the mean rainfall rate are less pronounced. This may support the notion that the dry season convection is stronger (instantaneously), since the overall convective cell coverage is also reduced during the dry season (e.g., Giangrande et al., 2016; Schiro, 2017). Wet and dry season convective rain fractions have similar values $(\sim 80 \%)$ throughout most of the day (Fig. $7 d$ ) and only diverge during the early morning hours when wet season convective rain fractions drop to as low as $20 \%$. These diurnal patterns suggest that organized MCSs pass over T3 primarily in the morning hours during the wet season but are infrequent and only have a small impact on the multi-month mean statistics.

Figure 8 plots seasonal breakdowns for the CF diurnal cycle from Fig. 6 for the wet and dry seasons. Pronounced CF profile increases are associated with deep convective and congestus clouds during the wet season, with the dry season having less organized cloud contributions (Ghate and Kollias, 2016). Overnight and/or pre-dawn deep convection and additional local congestus development are more common in the wet season. The distinct nighttime enhancement in stratiform precipitation (once again, often categorized under "deep convection" in Figs. 6d, 8g and h) during the wet season is consistent with previous findings that propagating convective cloud systems contribute to the observed diurnal cycle of deep convection (e.g., Burleyson et al., 2016; Tang et al., 2016). Early morning shallow cumulus CF profiles (Fig. 8a and b) indicate frequent low clouds during wet and dry seasons, consistent with a response to increased surface heating and an increase in the surface latent heat flux, with the wet season reporting additional shallow cloud development throughout the diurnal window (and the dry season consistent with elevated LCL heights). Two separate vertical peaks of shallow cumulus CF were observed between pre-dawn and early morning hours (03:00-09:00 LT) during the wet season: one right above the surface and the other at $2 \mathrm{~km}$ height. The surface peak is possibly associated with overnight fog being lifted with surface heating associated with the rising sun (e.g., Anber et al., 2015), while the elevated peak may be associated with radiative cooling of the residual boundary layer overnight. Cirrus CF stays elevated during the wet and dry seasons; however, cirrostratus/anvil CFs are substantially reduced during the dry season. This pattern suggests mostly a local deep convective contribution to cirrostratus/anvil during the dry season, with local convection and potentially some additional remnant anvil or decaying MCS cloud components advected over T3 during overnight hours under wet season conditions. Quantitative interpretation for these behaviors is challenging due to coupled cirrus-shallow cloud sampling factors during the overnight hours. For example, it is likely cirrus sampling is shielded (results stemming from an MPL detection) during the wet season due to the added presence of lower-level clouds and higher relative humidity/attenuation limiting the usefulness of the cloud radar. In contrast, clear low-level conditions during the overnight hours of the dry season would likely promote improved designation of cirrus. In this regard, wet and dry season cirrus cloud contrasts may be more pronounced than reported by this study.

As highlighted in Figs. 2 and 3, wet season thermodynamical conditions typically favor weaker CAPE, weaker CIN and higher RH in the lower to mid-atmospheric levels, while dry seasons feature stronger CAPE, stronger CIN and lower $\mathrm{RH}$ at the same levels. As inferred from the large-scale forcing fields in Fig. 4, wet season conditions favor higher column relative humidity, as well as heightened moisture convergence throughout the profile. The wet season also features more favorable omega fields at middle levels for shallow to deeper convective cloud transitions. This behavior is not surprising and also consistent with forcing datasets being constrained using mean domain precipitation estimates. However, as with first-year GoAmazon2014/5 studies (e.g., Collow et al., 2016), only weak correlations are found between cloud state and thermodynamic parameters (not shown). Nevertheless, coupled thermodynamical and environmental forcing conditions from Sect. 2 support these observations of more frequent cloudiness during the wet season, visible across almost all cloud categories (Fig. 8).

\subsection{Comparison of cloud observations with satellite: shallow cumulus representativeness}

An important consideration when interpreting ARM T3 observations is the spatiotemporal representativeness of the cloud fractions over T3 within this central Amazon region. Satellite observations provide one avenue to better understand the representativeness of the location, while also providing insights into the advantages afforded by ground-based ARM cloud observations. Several recent GoAmazon2014/5 studies including Burleyson et al. (2016) and Giangrande et al. (2016) have investigated the representativeness of the T3 site as compared to satellite and/or radar perspectives. In these studies, they found evidence suggesting that T3observed deep convection is well correlated with the regional cloud and precipitation to within a few hundred kilometers of the site. As a complementary reference, we approach the topic from a shallow cumulus perspective, as these clouds provide some of the better ground- and aircraft-based dataset opportunities collected during this campaign.

Figure 9 provides a diurnal comparison plot of shallow cumulus cloud fraction between T3 ground-based estimates, the Geostationary Operational Environmental Satellite (GOES) SatCORPS (Minnis et al., 2011) and the Moderate Resolution Imaging Spectroradiometer (MODIS; Plat- 
(a) Shallow/cirrus (wet)

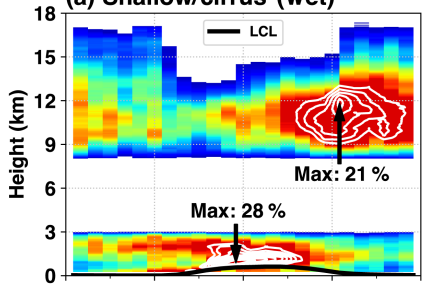

(e) Congestus (wet)
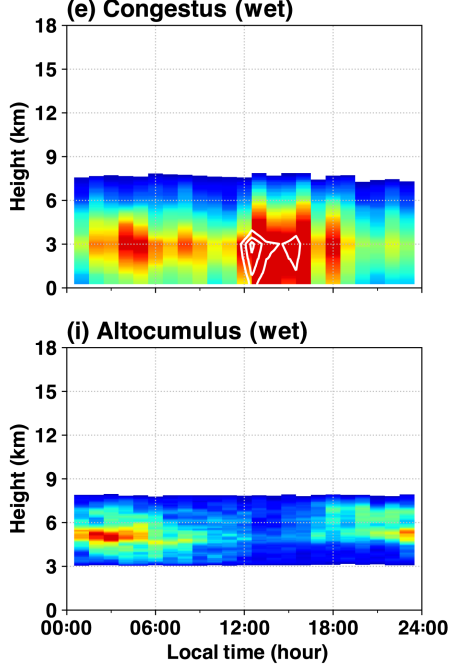

(b) Shallow/cirrus (dry)

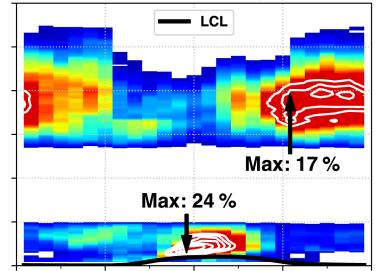

(f) Congestus (dry)

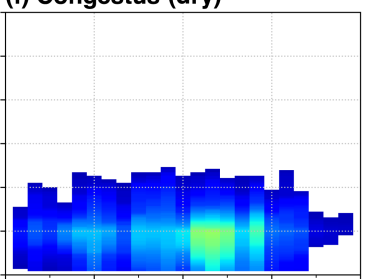

(j) Altocumulus (dry)

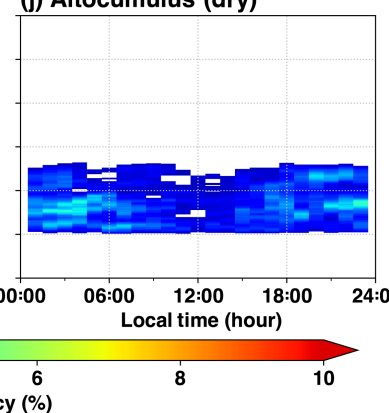

(c) Cirrostratus (wet)

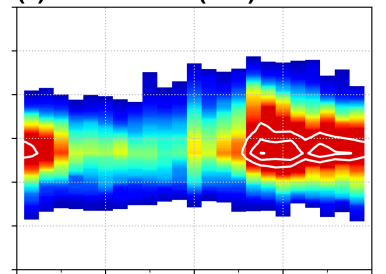

(g) Deep conv (wet)

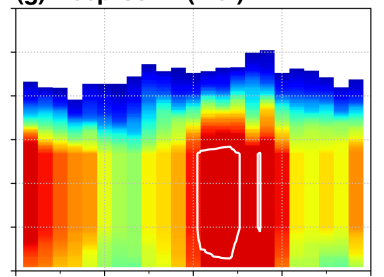

(k) Altostratus (wet)

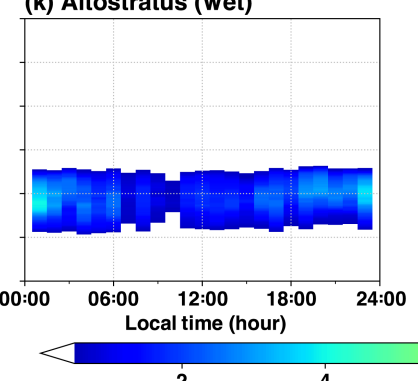

(d) Cirrostratus (dry)

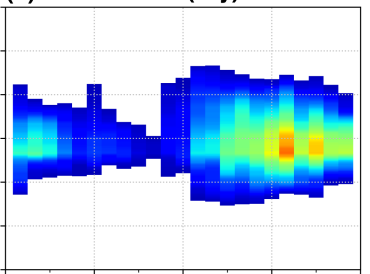

(h) Deep conv (dry)

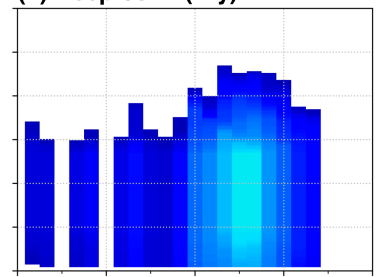

(I) Altostratus (dry)

Figure 8. As in Fig. 6 but for wet season and dry season conditions.
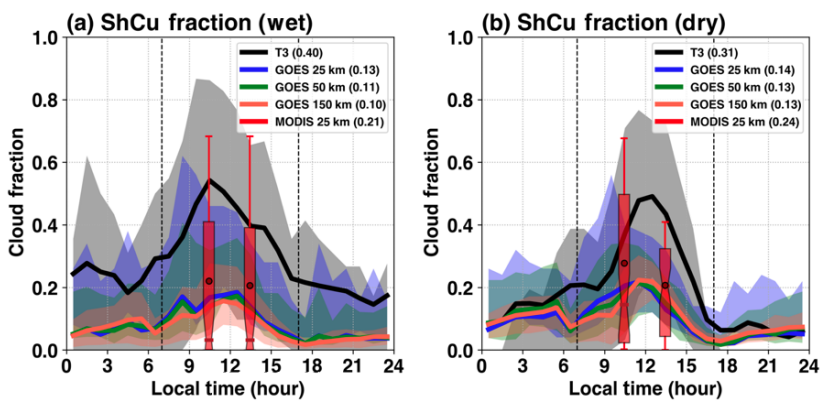

Figure 9. Diurnal comparison of shallow cumulus $(\mathrm{ShCu})$ cloud fraction estimates between ARM T3 (black lines and grey shading), MODIS (red box whiskers) and GOES (multi-color, contingent on spatial domain) centered on the ARM T3 site for (a) wet and (b) dry season breakdowns during February-December 2014. Values in the legend reflect an averaged value during daytime (07:00-17:00 LT, vertical dashed lines) hours. Shaded regions reflect the observational interquartile range. MODIS box-and-whisker notches show median values, circles show means, boxes show interquartile ranges and whiskers show 10th and 90th percentiles, respectively.

nick et al., 2003) products for wet and dry seasons (comparisons performed between February and December of 2014 when both satellite datasets are available). Both satellite

cloud products are based on multi-channel passive sensors on board, providing fundamentally different cloud detection techniques compared to active sensors at T3. We chose these satellite data products because they provide large area coverage and frequent updates, making the comparison with single-point surface observations more amenable. The cloud property retrievals are available at $4 \mathrm{~km}$ spatial and $30 \mathrm{~min}$ temporal resolution for GOES, and at $1 \mathrm{~km}$ spatial and two overpasses during $\sim$ 10:30 and $\sim$ 13:30 LT for MODIS. Shallow cumulus clouds are defined at pixel-level cloud-top height below $3 \mathrm{~km}$, consistent with T3 ground-based definitions. Shallow cumulus cloud fractions are then calculated at several spatial coverage domains (from 25 to $150 \mathrm{~km}$ ) for GOES and at $25 \mathrm{~km}$ domain for MODIS. We find that the GOES mean CF estimates are similar in their diurnal cycle and magnitude as a function of the domain size, with increasing variability in CF estimates (shadings) to the smaller domain sizes. The MODIS mean CF estimates are higher than those obtained from GOES but share similar diurnal patterns and ranges of variability to the GOES smaller domain estimates.

In comparison with the satellite observations, single-point T3 ground estimates of shallow cumulus are the largest and carry the largest observational spread but demonstrate diurnal and peak behaviors that are roughly comparable to the 
satellite counterparts. Discrepancies in CF estimate (mean) magnitude are not surprising, with the largest discrepancies found in the wet season. These differences may be related to several factors including the obscured view of shallow clouds from passive satellite retrievals, for example, due to the blockage from higher clouds (i.e., multi-layer clouds). Moreover, over the entire field campaign period, single-layer clouds occur $\sim 48 \%$ of the time, while multi-layer clouds occur $\sim 20 \%$ of the time. During the wet seasons, multi-layer clouds occur twice as often as during the dry seasons $(\sim 28 \%$ vs. $\sim 11 \%)$. The coarser resolution and/or sensitivity of the satellite platforms to shallower cumulus may also contribute to the lower mean CF values. The higher-resolution MODIS product shows higher shallow cumulus $\mathrm{CF}$ estimates than GOES during MODIS overpass times, demonstrating additional benefits of increased resolution in detecting shallow cumulus clouds, especially compared to ground-based active remote sensing observations. Finally, unavoidable discrepancies and variability still may trace to spatial domain versus column-temporal CF definition differences (e.g., Berg and Stull, 2002) or factors including localized circulations generated by river breezes (e.g., Burleyson et al., 2016). Overall, this shallow cumulus comparison between T3 ground-based and satellite observations suggests that mean cloud fractions near the T3 location should be representative of larger domain cloud properties to within a few hundred kilometers.

\section{Cloud-type influence on surface energy and fluxes}

AMF instrumentation provides unique capabilities to characterize the variability of clouds and their impact on the Amazon surface energy budget (e.g., Collow and Miller, 2016). Previously, Burleyson et al. (2015) quantified the diurnal cycle of surface cloud radiative effects (CREs) over the three ARM sites in the tropical western Pacific (TWP, e.g., Long et al., 2016; ARM, 2013) using long-term measurements of ARSCL cloud profiles and surface radiative flux analysis. CRE is defined as cloudy-sky downwelling flux minus clearsky downwelling flux. By breaking down the aggregate surface CRE by cloud type across the diurnal cycle, Burleyson et al. (2015) found that the largest source of shortwave surface CRE at these three TWP sites comes from low clouds due to their high frequency of occurrence. Although deep convective clouds have a strong influence on surface shortwave radiation when present, their aggregate impact is limited by a lower frequency of occurrence compared to shallow cumulus. Longwave CRE is typically a factor of 5-6 smaller than SW CRE (e.g., Culf et al., 1998; Malhi et al., 2002; Burleyson et al., 2015). This study will limit most interpretation to SW CRE. The 2-year deployment during GoAmazon2014/5 allows us to examine the impact of various cloud types on the surface energy budget over the Amazon, providing new details for targeted model improvements of cloud radiative effects in this climatically important but undersam- pled region. This deployment also provides a unique opportunity to contrast "green ocean" cloud radiative effects during GoAmazon2014/5 with tropical ARM fixed-site measurements in the TWP.

The frequency of occurrence for the lowest cloud types and their associated radiative fluxes (Tables 2 and 3 ) are composited into hourly bins across the diurnal cycle (Fig. 10). Table 3 is also complemented by Fig. 11 to better illustrate the diurnal cycle of those mean values and their variability for the complete record, including wet/dry season breakdowns. The methodology to produce the radiative fluxes in these tables is similar to Burleyson et al. (2015) to facilitate comparison with previous results over the three TWP sites. We utilize "as lowest cloud type" in the column designations in our analysis (e.g., second column in Table 2) because clouds closest to the surface typically have the larger impact on the surface radiative fluxes (Burleyson et al., 2015). However, we also note that it is not possible to separate the radiative impact of multi-layer clouds, and sample sizes are potentially too small to only consider single-layer cloud periods. For higheraltitude cloud types, the frequency as lowest cloud in the column is lower than the total cloud frequencies discussed in Sect. 3 (as reported in the first column of Table 2). The difference in frequencies is indicative of how often multi-layer clouds are present (e.g., cirrus clouds are often present above shallow cumulus).

One notable discrepancy with the previous study is that the instrumentation for classifying the clouds that produce significant precipitation (rain rate $>1 \mathrm{~mm} \mathrm{~h}^{-1}$ ) during GoAmazon2014/5 is better than the approach used by Burleyson et al. (2015) due to the merging of the RWP dataset. Specifically, cloud profiles with rain rate larger than $1 \mathrm{~mm} \mathrm{~h}^{-1}$ are discarded in Burleyson et al. (2015) but retained for our study. Therefore, we anticipate that cloud radiative effects from precipitating convective clouds (including both congestus and deep convection) may be more accurate than Burleyson et al. (2015).

\subsection{Bulk cloud radiative effects}

The average aggregated shortwave (SW) and longwave (LW) fluxes and CRE measured at the T3 site are given in Table 3, along with long-term results from the three TWP sites (Darwin, Manus, Nauru) as reported in Burleyson et al. (2015). SW CRE dominates (magnitude) as compared to LW CRE. The mean SW CRE $\left(-94.4 \mathrm{Wm}^{-2}\right)$ and LW CRE $\left(14.5 \mathrm{Wm}^{-2}\right)$ averaged across the diurnal cycle (nighttime included) over the entire GoAmazon2014/5 are most similar to those found at Manus, which is the cloudiest of the three TWP sites and most influenced by convection in the western Pacific warm pool. The Darwin, Australia, site has a strong monsoonal cycle (i.e., wet/dry season) and the Nauru site is strongly impacted by the El Niño-Southern Oscillation (ENSO) variability (Burleyson et al., 2015). Manus would be the one most qualitatively consistent with the GoA- 


\section{(a) Frequency}

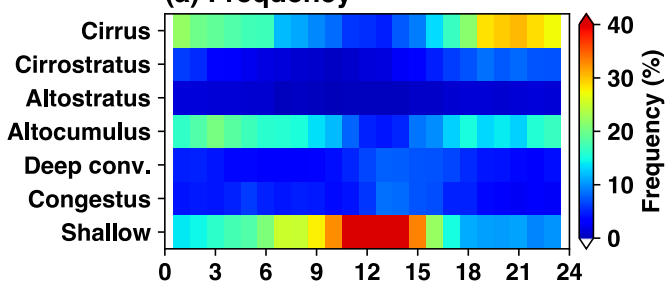

(c) Mean LW CRE

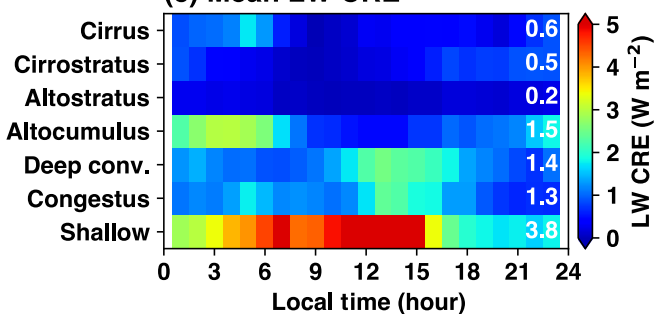

\section{(b) Conditional SW CRE}

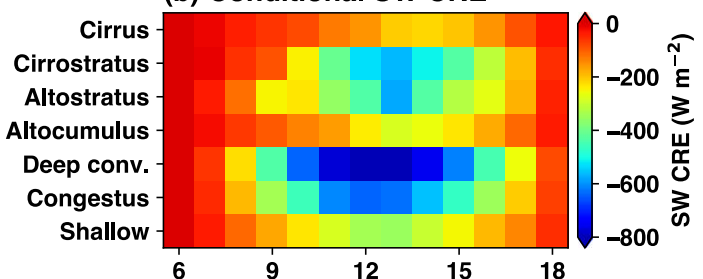

(d) Mean SW CRE

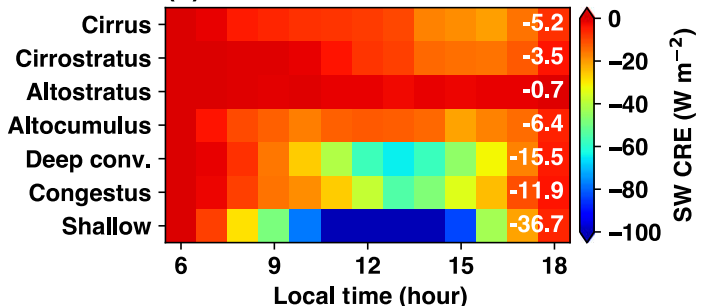

Figure 10. Mean cloud frequency and CRE for all GoAmazon2014/5 data. (a) Cloud frequency of occurrence as the lowest cloud in the column as a function of the diurnal cycle ( $x$ axis), (b) conditional SW CRE, (c) mean LW CRE (frequency of occurrence times for the conditional LW CRE) and (d) mean SW CRE (frequency of occurrence times for the conditional SW CRE). Note that panels (a, c) are for all hours and (b, d) are for daytime hours only. The white boxes are hours with insufficient data. The white numbers in panels (c, d) show the mean CRE values (in $\mathrm{Wm}^{-2}$ ) averaged across the diurnal cycle (including nighttime).

Table 3. Mean downwelling SW radiative flux (SWdn), estimated clear-sky SW radiative flux (CSWdn), aggregate SW cloud radiative effect (SW CRE; SWdn - CSWdn), downwelling LW radiative flux (LWdn), estimated clear-sky LW radiative flux (CLWdn) and aggregate LW cloud radiative effect (LW CRE; LWdn - CLWdn). All units are in $\mathrm{Wm}^{-2}$ and are averaged across the diurnal cycle. The Darwin, Manus and Nauru results are taken from Burleyson et al. (2015) (Table 3).

\begin{tabular}{|c|c|c|c|c|c|c|}
\hline & SWdn & CSWdn & SW CRE & LWdn & CLWdn & LW CRE \\
\hline \multicolumn{7}{|c|}{ Manaus (central Amazonia) } \\
\hline All data & 197.5 & 291.9 & -94.4 & 420.3 & 405.9 & 14.5 \\
\hline Wet seasons & 183.6 & 305.0 & -121.5 & 423.7 & 405.9 & 17.8 \\
\hline Dry seasons & 216.2 & 276.6 & -60.4 & 415.0 & 404.9 & 10.1 \\
\hline \multicolumn{7}{|l|}{ Darwin } \\
\hline All data & 232.4 & 293.4 & -61.0 & 407.0 & 394.6 & 12.4 \\
\hline Wet seasons & 226.5 & 321.5 & -95.0 & 427.9 & 411.5 & 16.4 \\
\hline Dry seasons & 239.1 & 262.7 & -23.5 & 384.2 & 376.4 & 7.8 \\
\hline \multicolumn{7}{|l|}{ Manus } \\
\hline All data & 205.1 & 299.8 & -94.7 & 423.5 & 408.2 & 15.3 \\
\hline \multicolumn{7}{|l|}{ Nauru } \\
\hline All data & 237.7 & 302.1 & -64.4 & 420.6 & 408.5 & 12.2 \\
\hline
\end{tabular}

mazon2014/5 "green ocean" moniker. During the wet season, SW CRE $\left(-121.5 \mathrm{Wm}^{-2}\right)$ is twice the dry season value $\left(-60.4 \mathrm{Wm}^{-2}\right)$, although CREs for this region of the Amazon basin are substantially larger than for Darwin during all seasons. However, although mean behaviors initially appear similar, the properties from individual cloud types are not necessarily consistent between, for example, Manus and Manaus (e.g., see Burleyson et al., 2015; Table 4). A more thorough breakdown of the factors driving these specific dif- ferences (e.g., the time of day when a given cloud type is more or less prevalent, the frequency of multi-layer clouds or variance in the clear-sky downwelling SW or LW flux) is recommended as a future activity from these GoAmazon2014/5 datasets.

Table 2 gives bulk cloud frequency and their radiative characteristics separated by cloud types and by season. The results reveal the averaged reduction of downwelling SW flux when a particular cloud type is present. Consistent with 
(a) All-sky SW down
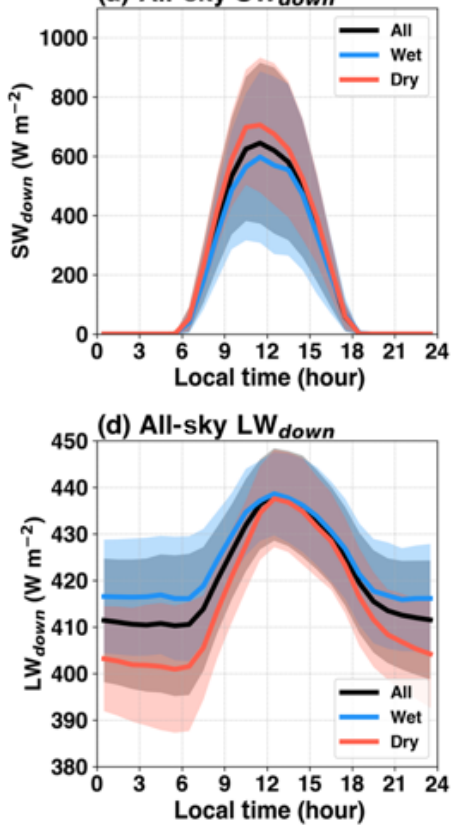

(b) Clear-sky SW down

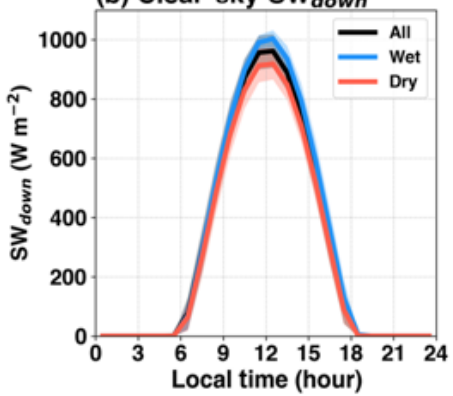

(e) Clear-sky LW down

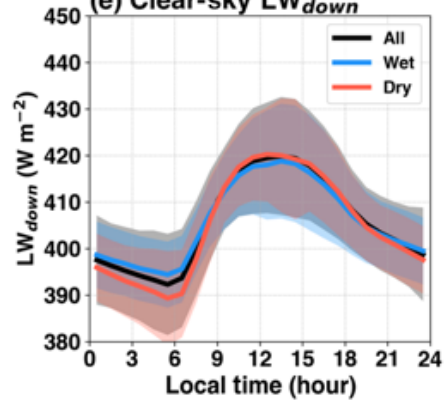

(c) SW CRE
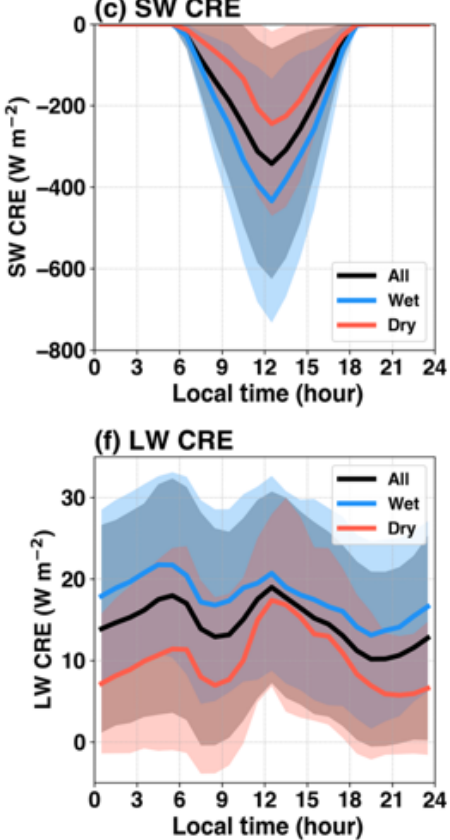

Figure 11. As in Table 3 except with the full diurnal cycle for the (a) mean downwelling SW radiative flux, (b) estimated clear-sky SW radiative flux, (c) aggregate SW cloud radiative effects, (d) downwelling LW radiative flux, (e) estimated clear-sky LW radiative flux and (f) aggregate $\mathrm{LW}$ cloud radiative effect. All units are in $\mathrm{Wm}^{-2}$. Shaded regions represent the observational standard deviation for these estimates during the hour.

(a) Frequency (Wet)

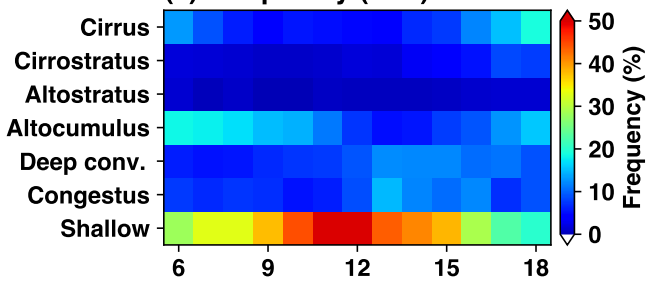

(c) Mean SW CRE (Wet)

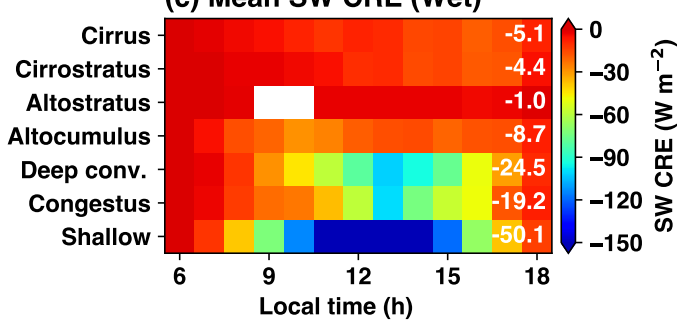

\section{(b) Frequency (Dry)}

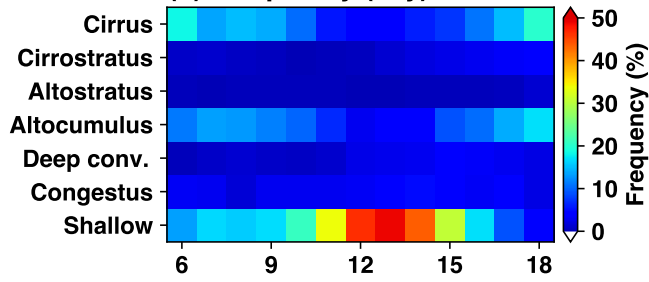

(d) Mean SW CRE (Dry)

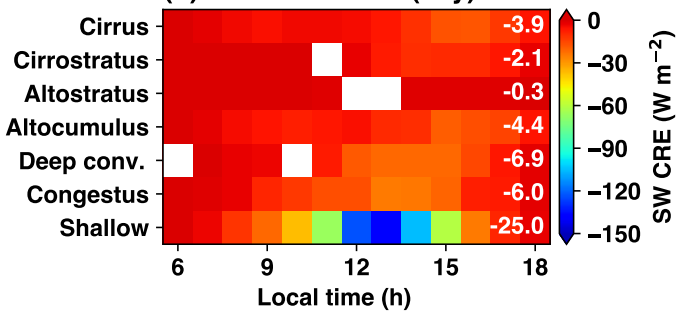

Figure 12. Wet $(\mathbf{a}, \mathbf{c})$ and dry $(\mathbf{b}, \mathbf{d})$ season comparisons for cloud frequency and SW CRE. (a, b) Cloud frequency of occurrence as the lowest cloud in the column, as a function of the diurnal cycle ( $x$ axis). (c, d) Mean SW CRE (frequency of occurrence times the conditional SW CRE). The white numbers in panels (c, d) show the mean CRE values (in $\mathrm{Wm}^{-2}$ ) averaged across the diurnal cycle (including nighttime). The white boxes represent hours with insufficient data.

the SW transmissivity results (Table 2) and those found by Burleyson et al. (2015), congestus and deep convective clouds dominate the conditional (e.g., not a mean property) SW CRE, while cirrus clouds have the smallest effect on downwelling SW flux. Note that the conditional CRE pre- sented in Table 2 includes both single-layer clouds, as well as when additional cloud layers are above the lowest detected cloud layer. This is done deliberately to be consistent with the method used by Burleyson et al. (2015) such that the GoAmazon2014/5 results can be directly compared 
with their long-term results from the ARM TWP sites. Examination of the averaged conditional SW CRE calculated using only single-layer clouds reveals a relative reduction of $\sim 26 \%$ for altocumulus and $\sim 20 \%$ for shallow cumulus clouds and negligible difference in other cloud types. The reduction in SW CRE when single-layer clouds are considered is likely caused by frequent multi-layer cloud occurrence of cirrus/cirrostratus clouds over shallow cumulus or altocumulus (i.e., artificially inflating the surface SW CRE of cumulus clouds due to additional SW flux reflection by the upper-level clouds). The difference in conditional SW CRE between single- and multi-layer clouds does not change their contribution to the average CRE as discussed below.

\subsection{Diurnal cycle of cloud radiative effects by cloud type}

Comparisons between wet and dry season diurnal behaviors for the frequency of the lowest clouds in the column and the associated mean SW CRE are shown in Fig. 12. Shallow cumulus clouds dominate the SW CRE in both seasons, although their frequency peaks $2 \mathrm{~h}$ earlier during wet season (10:00-11:00 LT) than during dry season (12:00-13:00 LT). While the dry season features reduced frequency and SW CRE of all cloud types, the contrast is most visible for the three convective cloud types. Shallow, congestus and deep convective cloud mean SW CRE in the wet season are 50, 69 and $72 \%$ larger than those in the dry season, respectively (their mean SW CRE values across the diurnal cycle are shown in Fig. 12c, d).

\subsection{Shallow cumulus cloud properties}

From the previous section, shallow cumulus (those most frequently observed during the campaign) are associated with large discrepancies in cloud radiative effects between the wet and dry seasons (Table 2 and Fig. 13). Further investigation into these clouds and their radiative differences is enabled using aircraft observations available during the GoAmazon2014/5 campaign IOPs. As discussed in Sect. 2.2, three cloud particle size distribution probes are combined to create the full DSD (Fig. 13). Combining the cloud microphysical properties in shallow cumulus measured by aircraft observations and the cloud macrophysical properties measured by ground-based instrumentations allows us to explain the cloud radiative effect differences from wet and dry seasons reported in the previous section.

Cloud particle size distributions (Fig. 13c) in the wet season are characterized by a lesser occurrence of small droplets and a more frequent occurrence of large droplets when compared with cumulus clouds in the dry season. Total number concentration of cloud drops is more than a factor of 2 larger in the dry season than in the wet season (Fig. 13b). However, the corresponding LWC is roughly the same between the seasons (Fig. 13d). In situ cloud condensation nuclei (CCN)
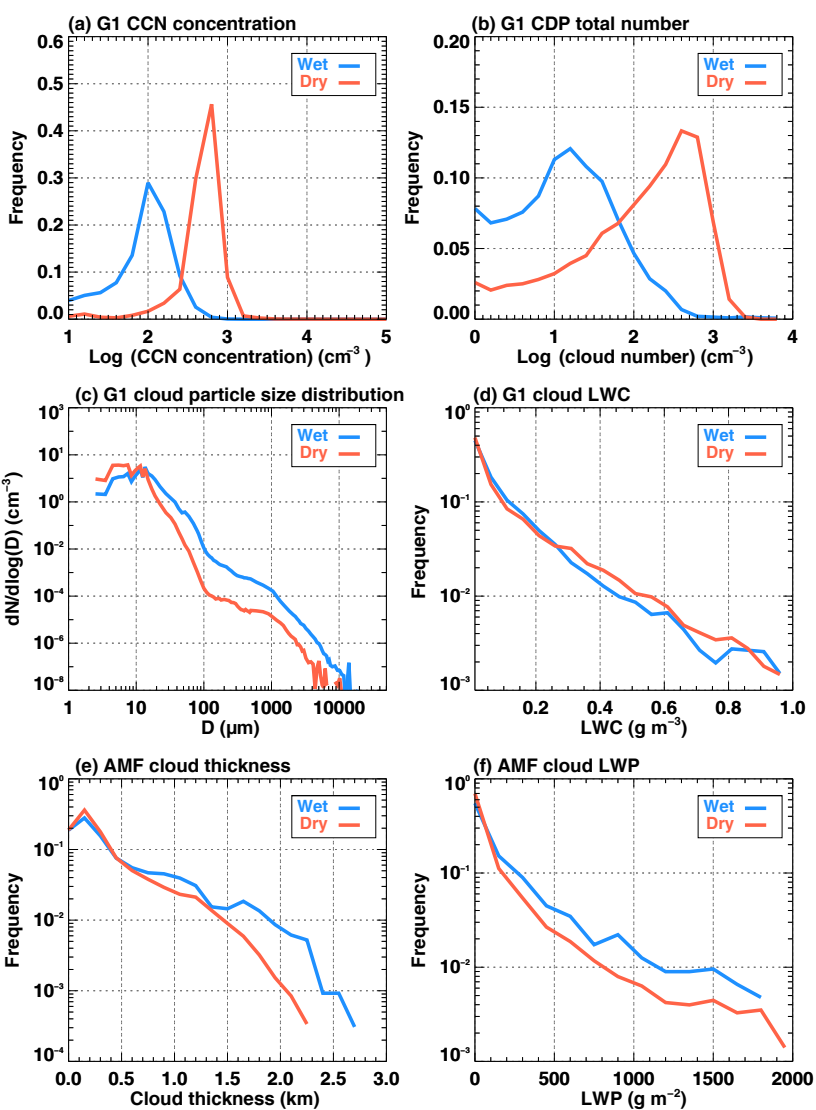

Figure 13. Shallow cumulus cloud micro- and macrophysics observed by AAF G1 aircraft and AMF surface instrumentation at the T3 site during the two IOPs in GoAmazon2014/5. (a) Cloud condensation nuclei number concentration, (b) cloud droplet total number concentration, (c) cloud particle size distribution, (d) cloud liquid water content (LWC), (e) cloud thickness and (f) cloud liquid water path (LWP).

concentration is also larger in the dry season than in the wet season (Fig. 13a). Aircraft cloud and CCN measurements are consistent with studies that show clouds influenced by aerosol tend to have larger concentrations of smaller droplets and fewer precipitation-sized drops for clouds with similar LWC (e.g., Twomey, 1974; Cecchini et al., 2016). Groundbased radar measurements of single-layer shallow cumulus clouds at the T3 site show thicker clouds occurring more frequently in the wet season (Fig. 13e). Likewise, more frequent occurrence of large liquid water path (LWP) from the T3 ground-based MWR in the wet season is consistent with the presence of more robust (i.e., vertically developed) shallow cumulus clouds (Fig. 13f). Therefore, shallow cumulus clouds in the wet season are characterized by fewer but more frequent larger cloud droplets, while those in the dry season are characterized by more frequent smaller cloud droplets (Fig. 13b, c). Interestingly, these differences in DSDs result in comparable LWC between the wet/dry seasons (Fig. 13d). As a result, the stronger shallow cumulus conditional SW 
CRE in the wet season, which reflects the difference in microphysical properties, mainly arises from higher values of vertically integrated properties such as LWP and cloud thickness (Fig. 13e, f).

\section{Discussion, summary and future opportunities}

This study documents the continuous observations collected by the DOE AMF and AAF facilities to characterize cloud properties, collocated large-scale environments and cloud radiative effects over the 2-year GoAmazon2014/5 campaign. This extended ground deployment included high temporal and vertical resolution cloud profiling instrumentation, enabling a unique perspective on various cloud types and their diurnal evolution to complement previous satellite-based perspectives over this undersampled region. Routine thermodynamic profiling over the diurnal cycle, targeted IOP aircraft sampling and collocated aerosol instrumentation support future opportunities to differentiate and interpret cloud life cycle and process factors influenced by environmental forcing controls and those influenced by coupled cloud-aerosol interactions within pristine and polluted conditions (e.g., Martin et al., 2017). Analysis performed in this study and by previous GoAmazon2014/5 works (Burleyson et al., 2016; Giangrande et al., 2016) suggests that both shallow cumulus and deep convection observed over the AMF site are representative of larger domain cloud properties to within a few hundred kilometers. These studies indicate the usefulness of the datasets collected during the campaign to enable future studies to better understand the forcing control of the diurnal cycle, seasonal variability of clouds in the central Amazon region and associated feedbacks to the climate system.

The propensity for cumulus to initiate, deepen and organize across the Amazon basin drives much of the observed wet and dry season CF profile diurnal contrasts. Amazon wet season environments promote enhanced shallow cumulus throughout the diurnal cycle, as well as additional deeper precipitating cloud development likely associated with reduced CIN, heightened moisture convergence and relative humidity through atmospheric middle levels. Wet season and transitional periods exhibiting sharper CAPE and CIN contrasts potentially enhance the likelihood for deep convection to develop, promoting anvil and trailing stratiform regions that carry into the overnight hours and propagate across the Amazon basin. Weaker secondary peaks in congestus CFs are also found during the wet season within pre-dawn hours, revealed with confidence from coupled ARM profiling observations. Nevertheless, relatively favorable thermodynamical conditions during both seasons support local congestus and deeper cloud formation for this ARM dataset, which includes over 200 days recording measurable rainfall. This regularly occurring daily precipitation is primarily attributed to isolated and locally driven convective cells, supported by the $76 \%$ rainfall accumulation associated with convective modes, as well as the pronounced diurnal cycle for this rainfall centered near local noon. These ideas and the representativeness of the T3 measurements for cloud studies beyond examples presented within this study for shallow cumulus may be further explored using spatial observations as available from collocated SIPAM radar observations during GoAmazon2014/5.

Congestus and deeper convection are also shown to dominate the conditional surface SW CRE, similar to results from previous tropical ARM analyses over the TWP region. As one possible example for the appropriateness of the Amazon "green ocean" moniker, mean CRE properties for the Amazon are found to be similar to the TWP ARM Manus location in the western Pacific warm pool that favors frequent tropical convection with complex influences from adjacent large islands within the maritime continent (e.g., Mather, 2005). However, a more thorough analysis is recommended, as these similarities in mean CRE properties do not always hold for individual cloud types. Similarly, a natural contrast between Amazon SW CRE behaviors and those from ARM Nauru observations stems from the strong ENSO-driven variability over this site as a key driver for cloud coverage (e.g., Jensen et al., 1998; Burleyson et al., 2015). The cumulative Amazon CRE is also larger when compared to the Darwin wet season (given the "dry" season for Darwin is void of substantial cloud/precipitation). This behavior is partially attributed to the Darwin monsoonal environments that fluctuate between wider-spread tropical "active" cloud conditions and continental "break" monsoonal regimes that promote stronger convection (e.g., Holland, 1986; May and Ballinger, 2007; Giangrande et al., 2014). Overall, cumulative results from CRE help emphasize the important role of shallow cumulus for the Amazon, including the dry season, and the favorable low-level conditions (e.g., weak ascending air motions, positive moisture advection and moist surface) throughout the year that promote elevated shallow cumulus frequency. Given this relative importance, these clouds must be properly simulated in both global and regional climate models if the surface radiative budget (that affects land-atmosphere interactions and subsequent convective cloud and precipitation formations over the T3 site) is to be properly represented.

Ground-based multi-sensor measurements and aircraft observations further support thicker cumulus clouds occurring more frequently in the wet season. These clouds are those that have larger LWP that would also promote the heightened SW CRE and LW CRE contributions. Aircraft and groundbased cloud and CCN measurements and properties for shallow cumulus clouds in this study also provides information on the role of the Manaus pollution plume in cumulus cloud evolution. A key motivation behind GoAmazon2014/5 was the opportunity to test various cloud-aerosol interactions in the Amazon. Shallow cumulus summaries provided in our study are consistent with the hypothesis that clouds influenced by aerosol tend to have a larger concentration of smaller droplets and fewer precipitation-sized drops for 
clouds with similar LWC. As the clean (wet) and polluted (dry) cloud conditions tend to align with large-scale regime thermodynamical controls, subsequent studies will need to differentiate the role of the Manaus plume that influences the observed differences in shallow cumulus microphysical properties and examine the extent that the reduced frequency for MCSs removes Manaus pollution. In that regard, impacts on shallow cumulus clouds could have potentially a more profound impact as far as how shallow clouds transition to deeper convection, hence affecting hydrological cycle and land-atmosphere feedbacks.

Data availability. All ARM datasets used for this study may be downloaded at http://www.arm.gov and associated with several "value added product" streams (e.g., ARM Climate Research Facility, 1993, 2001, 2005, 2009, 2013, 2014). MODIS Aqua and Terra, level L2, collection 6, cloud property data with $1 \mathrm{~km}$ resolution are obtained from NASA's Distributed Active Archive Centers (DAACs) https://earthdata.nasa.gov/about/daacs, (NASA, 2014a). These data are part of the NASA Earth Observing System Data and Information System (EOSDIS) managed by the NASA Earth Science Data and Information System (ESDIS) project. Cloud properties (including effective cloud-top heights) from the 13th Geostationary Operational Environmental Satellite (GOES-13) were derived via SatCORPS (Satellite Cloud Observations and Radiative Property retrieval System), a suite of algorithms including the four-channel VISST (visible infrared solar-infrared split-window technique) daytime algorithm, and nighttime three-channel SIST (solar-infrared infrared split-window technique) and SINT (solarinfrared infrared near-infrared technique), which are versions similar to those described by Minnis et al. (2011). This cloud and radiative property dataset with $4 \mathrm{~km}$ resolution ( $\mathrm{v} 4.1)$ was processed for the GoAmazon $2014 / 5$ domain covering $3^{\circ} \mathrm{N}-10^{\circ} \mathrm{S}, 50-70^{\circ} \mathrm{W}$. It was obtained from mid-February to December 2014, from the NASA Langley Research Center Cloud and Radiation Research Group (https://satcorps.larc.nasa.gov/ARM-GOAMAZON, NASA, $2014 \mathrm{~b})$. A subset of this dataset, covering the AMF and local vicinity $\left(5^{\circ} \times 5^{\circ}\right)$, can be obtained from the ARM archive.

Competing interests. The authors declare that they have no conflict of interest.

Special issue statement. This article is part of the special issue "Observations and Modeling of the Green Ocean Amazon (GoAmazon2014/5) (ACP/AMT/GI/GMD inter-journal SI)”. It is not associated with a conference.

Acknowledgements. This paper has been authored by employees of Brookhaven Science Associates, LLC, under contract no. DE-SC0012704 with the US Department of Energy (DOE). The publisher by accepting the paper for publication acknowledges that the United States Government retains a non-exclusive, paid-up, irrevocable, world-wide license to publish or reproduce the published form of this paper, or allow others to do so, for
United States Government purposes. Zhe Feng at the Pacific Northwest National Laboratory (PNNL) is supported by the US DOE, as part of the Atmospheric System Research (ASR) Program. The PNNL is operated for DOE by Battelle Memorial Institute under contract no. DE-AC05-76RL01830. Work at the Lawrence Livermore National Laboratory (LLNL) was supported by the DOE ARM program and performed under the auspices of the US DOE by LLNL under contract no. DE-AC52-07NA27344. Funding was also obtained from the US DOE, the São Paulo Research Foundation (FAPESP - 2009/15235-8), the Amazonas State University (UEA) and the Amazonas Research Foundation (FAPEAM $062.00568 / 2014)$. The work was conducted under scientific licenses 001030/2012-4, 001262/2012-2 and 00254/2013-9 of the Brazilian National Council for Scientific and Technological Development (CNPq). Institutional support was provided by the Central Office of the Large Scale Biosphere Atmosphere Experiment in Amazonia (LBA), the National Institute of Amazonian Research (INPA), the National Institute for Space Research (INPE) and the Brazil Space Agency (AEB). We also acknowledge the Atmospheric Radiation Measurement (ARM) Climate Research Facility, a user facility of the US DOE, Office of Science, sponsored by the Office of Biological and Environmental Research, and support from the ASR program of that office. The authors thank the three anonymous reviewers for their constructive comments that helped to improve the manuscript. The authors give additional thanks to Mark Miller (Rutgers University) for an internal review of this paper and acknowledge support from Duli Chand and Mandy Thieman for satellite datasets. The GoAmazon2014/5 GOES-13 satellite retrievals were also supported by the US Department of Energy, Office of Biological and Environmental Research, Atmospheric System Research Program award DE-SC0000991.

Edited by: Timothy Garrett

Reviewed by: three anonymous referees

\section{References}

Ackerman, T. P. and Stokes, G. M.: The Atmospheric Radiation Measurement Program, Phys. Today, 56, 38-44, doi:10.1063/1.1554135, 2003.

Alcântara, C. R., Dias, M., Silva, A. F., Souza, E. P., and Cohen, J. C. P.: Verification of the role of the low level jets in Amazon squall lines, Atmos. Res., 100, 36-44, 2011.

Anber, U., Gentine, P., Wang, S. G., and Sobel, A. H.: Fog and rain in the Amazon, P. Natl. Acad. Sci. USA, 112, 11473-11477, 2015.

Atmospheric Radiation Measurement (ARM): Climate Research Facility, updated hourly, Balloon-Borne Sounding System (SONDE), 3.21297 S 60.5981 W: ARM Mobile Facility (MAO) Manacapuru, Amazonas, Brazil; AMF1 (M1), compiled by: Holdridge, D., Kyrouac, J., and Coulter, R., Atmospheric Radiation Measurement (ARM) Climate Research Facility Data Archive, Oak Ridge, Tennessee, USA, Data set accessed at: https://doi.org/10.5439/1025284, 1993.

Atmospheric Radiation Measurement (ARM): Climate Research Facility, updated monthly, SCM-Forcing DATA from variational analysis (VARANAL), 2014-01-01 to 2015-12-31, 3.21297 S 60.5981 W: ARM Mobile Facility (MAO) Man- 
acapuru, Amazonas, Brazil; AMF1 (M1), compiled by: Tang, S., Xie, S., and Zhang, Y.: Atmospheric Radiation Measurement (ARM) Climate Research Facility Data Archive: Oak Ridge, Tennessee, USA, Data set accessed 2016-07-22 at: https://doi.org/10.5439/1273323, 2001.

Atmospheric Radiation Measurement (ARM): Climate Research Facility, updated hourly, W-Band (95 GHz) ARM Cloud Radar (WACR). 3.21297 S 60.5981 W: ARM Mobile Facility (MAO) Manacapuru, Amazonas, Brazil; AMF1 (M1), compiled by: Bharadwaj, N., Nelson, D., Isom, B., Hardin, J., Lindenmaier, I., Johnson, K., and Matthews, A., Atmospheric Radiation Measurement (ARM) Climate Research Facility Data Archive: Oak Ridge, Tennessee, USA, Data set accessed at: https://doi.org/10.5439/1025317, 2005.

Atmospheric Radiation Measurement (ARM): Climate Research Facility, Updated hourly, Radar Wind Profiler (1290RWPPRECIPMOM), compiled by: Coulter, R., Martin, T., and Muradyan, P.: Atmospheric Radiation Measurement (ARM) Climate Research Facility Data Archive: Oak Ridge, Tenn, https://doi.org/10.5439/1025128, 2009.

Atmospheric Radiation Measurement (ARM): Climate Research Facility, updated hourly, Radiative Flux Analysis (RADFLUX1LONG), 2014-01-01 to 2015-12-31, ARM Mobile Facility (MAO) Manacapuru, Amazonas, Brazil; AMF1 (M1), compiled by: Long, C., Gaustad, K., and Riihimaki, L.: Atmospheric Radiation Measurement (ARM) Climate Research Facility Data Archive: Oak Ridge, Tennessee, USA, Data set accessed at: https://doi.org/10.5439/1157585, 2013.

Atmospheric Radiation Measurement (ARM): Aerial Facility (AAF), updated per flights, Campaign datasets for Observations and Modeling of the Green Ocean Amazon (GOAMAZON), Jan. - Oct. 2014, 3.1190 S, $60.0217^{\circ} \mathrm{W}$ : Gulfstream 159 Aircraft (F1),compiled by: Martin, S., Mei, F., Alexander, L., Artaxo, P., Barbosa, H., Bartholomew, M. J., Biscaro, T., Buseck, P., Chand, D., Comstock, J., Dubey, M., Godstein, A., Guenther, A., Hubbe, J., Jardine, K., Jimenez, J., Kim, S., Kuang, C., Laskin, A., Long, C., Paralovo, S., Petaja, T., Powers, H., Schumacher, C., Sedlacek, A., Senum, G., Smith, J., Shilling, J., Springston, S., Thayer, M., Tomlinson, J., Wang, J., and Xie, S., ARM Data Archive: Oak Ridge, Tennessee, USA, Data set accessed 201605-30 at: https://doi.org/10.5439/1346559, 2014.

Bedacht, E., Gulev, S. K., and Macke, A.: Intercomparison of global cloud cover fields over oceans from the VOS observations and NCEP/NCAR reanalysis, Int. J. Clim., 27, 1707-1719, https://doi.org/10.1002/joc.1490, 2007.

Berg, L. K. and Stull, R. B.: Accuracy of point and line measures of boundary layer cloud amount, J. Appl. Meteor., 41, 640-650, 2002.

Betts, A. K., Fuentes, J., Garstang, M., and Ball, J. H.: Surface diurnal cycle and Boundary Layer structure over Rondonia during the rainy season, J. Geophys. Res., 107, 8065, https://doi.org/10.1029/2001JD000356, 2002.

Burleyson, C. D., Long, C. N., and Comstock, J. M.: Quantifying Diurnal Cloud Radiative Effects by Cloud Type in the Tropical Western Pacific, J. Appl. Meteorol. Clim., 54, 1297-1312, 2015.

Burleyson, C. D., Feng, Z., Hagos, S. M., Fast, J., Machado, L. A. T., and Martin, S. T.: Spatial Variability of the Background Diurnal Cycle of Deep Convection around the GoAma- zon2014/5 Field Campaign Sites, J. Appl. Meteor. Climatol., https://doi.org/10.1175/JAMC-D-15-0229.1, 2016.

Cecchini, M. A., Machado, L. A. T., Comstock, J. M., Mei, F., Wang, J., Fan, J., Tomlinson, J. M., Schmid, B., Albrecht, R., Martin, S. T., and Artaxo, P.: Impacts of the Manaus pollution plume on the microphysical properties of Amazonian warmphase clouds in the wet season, Atmos. Chem. Phys., 16, 70297041, https://doi.org/10.5194/acp-16-7029-2016, 2016.

Clothiaux, E. E., Ackerman, T. P., Mace, G. G., Moran, K. P., Marchand, R. T., Miller, M. A., and Martner, B. E.: Objective determination of cloud heights and radar reflectivities using a combination of active remote sensors at the ARM CART sites, J. Appl. Meteorol., 39, 645-665, https://doi.org/10.1175/15200450(2000)039<0645:ODOCHA >2.0.CO;2, 2000.

Cohen, J. C. P., Silva Dias, M. A. F., and Nobre, C. A.: Environmental Conditions Associated With Amazonian Squall Lines: A Case Study, Mon. Weather Rev., 123, 3163-3174, 1995. ë

Collow, A. B. and Miller, M. A.: The Seasonal Cycle of the Radiation Budget and Cloud Radiative Effect in the Amazon Rain Forest of Brazil, J. Climate, 29, 7703-7722, https://doi.org/10.1175/JCLI-D-16-0089.1, 2016.

Collow, A. B., Miller, M. A., and Trabachino, L. C.: Cloudiness over the Amazon rainforest: Meteorology and thermodynamics, J. Geophys. Res.-Atmos., 121, 7990-8005, https://doi.org/10.1002/2016JD024848, 2016.

Comstock, J. M., Ackerman, T. P., and Mace, G. G.: Groundbased lidar and radar remote sensing of tropical cirrus clouds at Nauru Island, Cloud statistics and radiative impacts, J. Geophys. Res., 107, 4714, https://doi.org/10.1029/2002JD002203, 2002.

Culf, A. D., Fisch, G., Lean, J., and Polcher, J.: A comparison of Amazonian climate data with general circulation model simulations, J. Climate, 11, 2764-2773, https://doi.org/10.1175/15200442(1998)011<2764:ACOACD>2.0.CO;2, 1998.

Del Genio, A. D.: Representing the sensitivity of convective cloud systems to tropospheric humidity in general circulation models, Surv. Geophys., 33, 637-656, https://doi.org/10.1007/s10712011-9148-9, 2012.

Dos Santos, M. J., Silva Dias, M. A. F., and Freitas, E. D.: Influence of local circulations on wind moisture and precipitation close to Manaus City, Amazon Region - Brazil, J. Geophys. Res., 119, 233-249 https://doi.org/10.1002/2014JD021969, 2014.

Feng, Z., Dong, X. Q., and Xi, B. K.: A Method to Merge WSR-88D Data with ARM SGP Millimeter Cloud Radar Data by Studying Deep Convective Systems, J. Atmos. Ocean. Technol., 26, 958971, 2009.

Feng, Z., McFarlane, S. A., Schumacher, C., Ellis, S., Comstock, J., and Bharadwaj, N.: Constructing a Merged Cloud-Precipitation Radar Dataset for Tropical Convective Clouds during the DYNAMO/AMIE Experiment at Addu Atoll, J. Atmos. Ocean. Technol., 31, 1021-1042, 2014.

Fisch, G., Tota, J., Machado, L. A. T., Silva Dias, M. A. F., Lyra, R. F. D., Nobre, C. A., Dolman, A. J., and Gash, J. H. C.: The convective boundary layer over pasture and forest in Amazonia, Theor. Appl. Climatol., 78, 47-59, 2004.

$\mathrm{Fu}, \mathrm{R}$. and $\mathrm{Li}, \mathrm{W}$.: Influence of land surface on transition from dry to wet season over the Amazonia, Theor. Appl. Climatol., 78, 97-110, 2004 
Fu, R. and Zhu, B., and Dickinson, R.: How do the atmosphere and land surface influence the seasonal changes of convection in tropical Amazon?, J. Climate, 12, 1306-1321, 1999.

Ghate, V. P. and Kollias, P.: On the Controls of Daytime Precipitation in the Amazonian Dry Season, J. Hydromet., https://doi.org/10.1175/JHM-D-16-0101.1, 2016.

Giangrande, S. E., Luke, E. P., and Kollias, P.: Characterization of vertical velocity and drop size distribution parameters in widespread precipitation at ARM facilities, J. Appl. Meteor. Climatol., 51, 380-391, 2012.

Giangrande, S. E., Collis, S., Straka, J., Protat, A., Williams, C., and Krueger, S.: A summary of convective-core vertical velocity properties using ARM UHF wind profilers in Oklahoma, J. Appl. Meteor. Climatol., 52, 2278-2295, https://doi.org/10.1175/JAMC-D-12-0185.1, 2013.

Giangrande, S. E., Bartholomew, M. J., Pope, M., Collis, S., and Jensen, M. P.: A summary of precipitation characteristics from the 2006-11 northern Australian wet seasons as revealed by ARM disdrometer research facilities (Darwin, Australia), J. Appl. Meteor. Climatol., 53, 1213-1231, 2014.

Giangrande, S. E., Toto, T., Jensen, M. P., Bartholomew, M. J., Feng, Z., Protat, A., Williams, C. R., Schumacher, C., and Machado, L.: Convective cloud vertical velocity and massflux characteristics from radar wind profiler observations during GoAmazon2014/5, J. Geophys. Res.-Atmos., 121, 1289112913, https://doi.org/10.1002/2016JD025303, 2016.

Holland, G. J.: Interannual variability of the Australian summer monsoon at Darwin: 1952-82, Mon. Weather Rev., 114, 594604, 1986.

Houze, R. A., Rasmussen, K. L., Zuluaga, M. D., and Brodzik, S. R.: The variable nature of convection in the tropics and subtropics: A legacy of 16 years of the Tropical Rainfall Measuring Mission satellite, Rev. Geophys., 53, 994-1021, 2015.

Jensen, M. P., Mather, J. H., and Ackerman, T. P.: Observations of the 1997-98 warm ENSO event at the Manus Island ARM site, Geophys. Res. Lett., 25, 4517-4520, 1998.

Jensen, M. P., Toto, T., Troyan, D., Ciesielski, P. E., Holdridge, D., Kyrouac, J., Schatz, J., Zhang, Y., and Xie, S.: The Midlatitude Continental Convective Clouds Experiment (MC3E) sounding network: operations, processing and analysis, Atmos. Meas. Tech., 8, 421-434, https://doi.org/10.5194/amt-8421-2015, 2015.

Klein, S. A. and Del Genio, A. D.: ARM's Support for GCM Improvement: A White Paper, U.S. Department of Energy, DOE/SC-ARM/P-06-012, Washington, D.C, 2006.

Kollias, P., Albrecht, B. A., Clothiaux, E. E., Miller, M. A., Johnson, K. L., and Moran, K. P.: The atmospheric radiation measurement program cloud profiling radars: An evaluation of signal processing and sampling strategies, J. Atmos. Ocean. Technol., 22, 930-948, 2005.

Kollias, P., Miller, M. A., Johnson, K. L., Jensen, M. P., and Troyan, D. T.: Cloud, thermodynamic, and precipitation observations in West Africa during 2006, J. Geophys. Res., 114, D00E08, https://doi.org/10.1029/2008JD010641, 2009.

Kollias, P., Jo, I., Borque, P., Tatarevic, A., Lamer, K., Bharadwaj, N., Widener, K., Johnson, K., and Clothiaux, E. E.: Scanning ARM cloud radars, Part II: Data quality control and processing, J. Atmos. Ocean. Technol., 31, 583-598, https://doi.org/10.1175/JTECH-D-13-00045.1, 2014.
Lamer, K. and Kollias, P.: Observations of fair-weather cumuli over land: Dynamical factors controlling cloud size and cover, Geophys. Res. Lett., 42, 8693-8701, https://doi.org/10.1002/2015GL064534, 2015.

Lawson, R. P., O'Connor, D., Zmarzly, P., Weaver, K., Baker, B., and Mo, Q. S.: The 2D-S (Stereo) Probe: Design and Preliminary Tests of a New Airborne, High-Speed, High-Resolution Particle Imaging Probe, J. Atmos. Ocean. Technol., 23, 1462-1477, https://doi.org/10.1175/JTECH1927.1, 2006.

$\mathrm{Li}, \mathrm{W}$. and Fu, R.: Transition of the large-scale atmospheric and land surface conditions from dry to wet season over Amazonia as diagnosed by the ECMWF Re-analysis, J. Climate, 17, 26372651, 2004.

Liu, S. and Liang, X. Z.: Observed diurnal cycle climatology of planetary boundary layer height, J. Climate, 23, 5790-5807, 2010.

Long, C. N. and Ackerman, T. P.: Identification of clear skies from broadband pyranometer measurements and calculation of downwelling shortwave cloud effects, J. Geophys. Res., 105, 1560915626, 2000.

Long, C. N. and Turner, D. D.: A method for continuous estimation of clear-sky downwelling longwave radiative flux developed using ARM surface measurements, J. Geophys. Res., 113, D18206, https://doi.org/10.1029/2008JD009936, 2008.

Long, C. N., Mather, J. H., and Ackerman, T. P.: The ARM Tropical Western Pacific (TWP) sites, The Atmospheric Radiation Measurement (ARM) Program: The First 20 Years, Meteor. Monogr., 57, Amer. Meteor. Soc., https://doi.org/10.1175/AMSMONOGRAPHS-D-15-0024.1, 2016.

Machado, L. A. T., Laurent, H., Dessay, N., and Miranda, I.: Seasonal and diurnal variability of precipitation over Amazon and its impact on convection over the Amazonia: A comparison of different vegetation types and large scale forcing, Theor. Appl. Climatol., 78, 61-77, https://doi.org/10.1007/s00704-004-00449, 2004.

Malhi, Y., Pegoraro, E., Nobre, A. D., Pereira, M. G. P., Grace, J., Culf, A. D., and Clement, R.: Energy and water dynamics of a central Amazonian rain forest, J. Geophys. Res., 107, 8061, https://doi.org/10.1029/2001JD000623, 2002.

Marengo, J. A., Fisch, G. F., Alves, L. M., Sousa, N. V., $\mathrm{Fu}$, R., and Zhuang, Y.: Meteorological context of the onset and end of the rainy season in Central Amazonia during the GoAmazon2014/5, Atmos. Chem. Phys., 17, 7671-7681, https://doi.org/10.5194/acp-17-7671-2017, 2017.

Martin, S. T., Artaxo, P., Machado, L. A. T., Manzi, A. O., Souza, R. A. F., Schumacher, C., Wang, J., Andreae, M. O., Barbosa, H. M. J., Fan, J., Fisch, G., Goldstein, A. H., Guenther, A., Jimenez, J. L., Pöschl, U., Silva Dias, M. A., Smith, J. N., and Wendisch, M.: Introduction: Observations and Modeling of the Green Ocean Amazon (GoAmazon2014/5), Atmos. Chem. Phys., 16, 47854797, https://doi.org/10.5194/acp-16-4785-2016, 2016.

Martin, S. T., Artaxo, P., Machado, L., Manzi, A. O., Souza, R. A., Schumacher, C., Wang, J., Biscaro, T., Brito, J., Calheiros, A., Jardine, K., Medeiros, A., Portela, B., de Sá, S. S., Adachi, K., Aiken, A. C., Albrecht, R., Alexander, L., Andreae, M. O., Barbosa, H. M., Buseck, P., Chand, D., Comstock, J. M., Day, D. A., Dubey, M., Fan, J., Fast, J., Fisch, G., Fortner, E., Giangrande, S., Gilles, M., Goldstein, A. H., Guenther, A., Hubbe, 
J., Jensen, M., Jimenez, J. L., Keutsch, F. N., Kim, S., Kuang, C., Laskin, A., McKinney, K., Mei, F., Miller, M., Nascimento, R., Pauliquevis, T., Pekour, M., Peres, J., Petäjä, T., Pöhlker, C., Pöschl, U., Rizzo, L., Schmid, B., Shilling, J. E., Dias, M. A., Smith, J. N., Tomlinson, J. M., Tóta, J., and Wendisch, M.: The Green Ocean Amazon Experiment (GoAmazon2014/5) Observes Pollution Affecting Gases, Aerosols, Clouds, and Rainfall over the Rain Forest, Bull. Am. Meteorol. Soc., 98, 981-997, https://doi.org/10.1175/BAMS-D-15-00221.1, 2017.

Mather, J. H.: Seasonal variability in clouds and radiation at the Manus ARM site, J. Climate, 18, 2417-2428, 2005.

Mather, J. H. and Voyles, J. W.: The Arm Climate Research Facility: A Review of Structure and Capabilities, Bull. Am. Meteor. Soc., 94, 377-392, 2013.

May, P. T. and Ballinger, A.: The statistical characteristics of convective cells in a monsoon regime (Darwin, Northern Australia), Mon. Weather Rev., 135, 82-92, 2007.

McFarlane, S. A., Long, C. N., and Flaherty, J.: A climatology of surface cloud radiative effects at the ARM tropical western Pacific sites, J. Appl. Meteorol. Clim., 52, 996-1013, https://doi.org/10.1175/Jamc-D-12-0189.1, 2013.

Miller, M. A., Nitschke, K., Ackerman, T. P., Ferrell, W., Hickmon, N., and Ivey, M.: The Atmospheric Radiation Measurement Mobile Facility, Chapter, AMS Monograph, The first 20 years of ARM, 2014.

Minnis, P., Sun-Mack, S., Young, D. F., Heck, P. W., Garber, D. P., Chen, Y., Spangenberg, D. A., Arduini, R. F., Trepte, Q. Z., Smith, W. L., Ayers, J. K., Gibson, S. C., Miller, W. F., Hong, G., Chakrapani, V., Takano, Y., Liou, K. N., Xie, Y., and Yang, P.: CERES Edition-2 cloud property retrievals using TRMM VIRS and Terra and Aqua MODIS data, Part I: Algorithms, IEEE T. Geosci. Remote, 49, 4374-4400, 2011.

Misra, V.: Coupled air, sea, and land interactions of the South American monsoon, J. Climate, 21, 6389-6403, https://doi.org/10.1175/2008JCLI2497.1, 2008.

NASA: MODIS Aqua, Terra Collection 6 product, https://doi.org/10.5067/MODIS/MYD06_L2.006 (Aqua), https://doi.org/10.5067/MODIS/MOD06_L2.006 (Terra), date accessed: July 2017, 2014a.

NASA: SatCORPS GOES13-derived Cloud and Radiative Property Dataset: GO-AMAZON version 4.1, https://satcorps.larc.nasa. gov/prod/exp/amf_goamazon/visst-pixel-netcdf-ver-4_1/2014, date accessed: 1 February 2017, 2014b.

Nobre, P., Malagutti, M., Urbano, D. F., De Almeida, R. A. F., and Giarolla, E.: Amazon deforestation and climate change in a coupled model simulation, J. Climate, 22, 5686-5697, 2009.

Nunes, A. M. P., Silva Dias, M. A. F., Anselmo, E. M., and Morales, C. A.: Severe Convection Features in the Amazon Basin: A TRMM-Based 15-Year Evaluation, Front. Earth Sci., 2016/000037, 2016.

Oue, M., Kollias, P., North, K. W., Tatarevic, A., Endo, S., Vogelmann, A. M., and Gustafson, W. I. Jr.: Estimation of cloud fraction profile in shallow convection using a scanning cloud radar, Geophys. Res. Lett., 43, 10998-11006, https://doi.org/10.1002/2016GL070776, 2016.

Platnick, S., King, M. D., Ackerman, S. A., Menzel, W. P., Baum, B. A., Riédi, J. C., and Frey, R. A.: The MODIS cloud products: Algorithms and examples from Terra, IEEE T. Geosci. Remote, 41, 459-473, 2003.
Richter, I. and Xie, S.: On the origin of equatorial Atlantic biases in coupled general circulation models, Clim. Dynam., 31, 587-598, doi:10.1007/s00382-008-0364-z, 2008.

Romatschke, U. and Houze Jr. R. A.: Extreme Summer Convection in South America, J. Climate, 23, 3761-3791, https://doi.org/10.1175/2010JCLI3465.1, 2010.

Rossow, W. B., Tselioudis, G., Polak, A., and Jakob, C.: Tropical climate described as a distribution of weather states indicated by distinct mesoscale cloud property mixtures, Geophys. Res. Lett., 32, L21812, https://doi.org/10.1029/2005GL024584, 2005.

Saraiva, I., Silva Dias, M. A. F., Morales, C. A. R., and Saraiva, J. M. B.: Regional Variability of Rain Clouds in the Amazon Basin as Seen by a Network of Weather Radars, J. Appl. Meteorol. Clim., 55, 2657-2675, 2016.

Schiro, K. A., Neelin, J. D., Adams, D. K., and Linter, B. R.: Deep convection and column water vapor over tropical land versus tropical ocean: A comparison between the Amazon and the tropical western Pacific, J. Atmos. Sci., 73, 4043-4063, https://doi.org/10.1175/JAS-D-16-0119.1, 2016.

Schiro, K. A.: Thermodynamic Controls on Deep Convection in the Tropics: Observations and Applications to Modeling, Ph.D. thesis, University of California, Los Angeles, CA, 148 pp., 2017.

Schmid, B., Ellingson, R. G., and McFarquhar, G. M.: ARM Aircraft Measurements, The Atmospheric Radiation Measurement (ARM) Program: The First 20 Years, Meteor. Monogr., 57, Amer. Meteor. Soc., 2016.

Silva Dias, M. A. F., Dias, P. L. S., Longo, M., Fitzjarrald, D. R., and Denning, A. S.: River breeze circulation in eastern amazonia: observations and modelling results, Theoretical and Applied Climatology, Springer, 78, 111-121, 2004.

Steiner, M., Houze Jr., R. A., and Yuter, S.: Climatological characterization of three-dimensional storm structure from operational radar and rain gauge data, J. Appl. Meteor., 34, 1978-2007, https://doi.org/10.1175/15200450(1995)034<1978:CCOTDS>2.0.CO;2, 1995.

Stokes, G. M. and Schwartz, S. E.: The Atmospheric Radiation Measurement (ARM) Program: Programmatic background and design of the cloud and radiation test bed, Bull. Am. Meteor. Soc., 75, 1201-1221, 1994.

Tang, S., Xie, S., Zhang, Y., Zhang, M., Schumacher, C., Upton, H., Jensen, M. P., Johnson, K. L., Wang, M., Ahlgrimm, M., Feng, Z., Minnis, P., and Thieman, M.: Large-scale vertical velocity, diabatic heating and drying profiles associated with seasonal and diurnal variations of convective systems observed in the GoAmazon2014/5 experiment, Atmos. Chem. Phys., 16, 14249-14264, https://doi.org/10.5194/acp-16-14249-2016, 2016.

Tridon, F., Battaglia, A., Kollias, P., Luke, E., and Williams, C. R.: Signal postprocessing and reflectivity calibration of the Atmospheric Radiation Measurement $915-\mathrm{MHz}$ wind profilers, J. Atmos. Oceanic Technol., 30, 1038-1054, 2013.

Twomey, S.: Pollution and the Planetary Albedo, Atmos. Environ., 8, 1251-1256, 1974.

Wilkinson, J. M., Hogan, R. J., Illingworth, A. J., and Benedetti, A.: Use of a lidar forward model for global comparisons of cloud fraction between the ICESat lidar and the ECMWF model, Mon. Weather Rev., 136, 3742-3759, 2008.

Williams, E., Rosenfeld, D., Madden, N., Gerlach, J., Gears, N., Atkinson, L., Dunnemann, N., Frostrom, G., Antonio, M., Biazon, B., Camargo, R., Franca, H., Gomes, A., Lima, M., 
Machado, R., Manhaes, S., Nachtigall, L., Piva, H., Quintiliano, W., Machado, L., Artaxo, P., Roberts, G., Renno, N., Blakeslee, R., Bailey, J., Boccippio, D., Betts, A., Wolff, D., Roy, B., Halverson, J., Rickenbach, T., Fuentes, J., and Avelino, E.: Contrasting convective regimes over the Amazon: Implications for cloud electrification, J. Geophys. Res., 107, 8082, https://doi.org/10.1029/2001JD000380, 2002.

Wu, W., Liu, Y., Jensen, M. P., Toto, T., Foster, M. J., and Long, C. N.: A comparison of multiscale variations of decade-long cloud fractions from six different platforms over the Southern Great Plains in the United States, J. Geophys. Res., 119, 3438-3459, https://doi.org/10.1002/2013JD019813, 2014.

Xie, S., Cederwall, R. T., and Zhang, M. H.: Developing long-term single-column model/cloud system-resolving model forcing using numerical weather prediction products constrained by surface and top of the atmosphere observations, J. Geophys. Res., 109, D01104, https://doi.org/10.1029/2003JD004045, 2004.
Xie, S., Zhang, Y., Giangrande, S. E., Jensen, M. P., McCoy, R., and Zhang, M.: Interactions between cumulus convection and its environment as revealed by the MC3E sounding array, J. Geophys. Res.-Atmos., 119, 11784-11808, https://doi.org/10.1002/2014JD022011, 2014.

Yin, L., Fu, R., Shevliakova, E., and Dickinson, R.: How well can CMIP5 simulate precipitation and its controlling processes over tropical South America?, Clim. Dynam., 41, 3127-3143, https://doi.org/10.1007/s00382-012-1582-y, 2013.

Zhang, M. and Lin, J.: Constrained Variational Analysis of Sounding Data Based on Column-Integrated Budgets of Mass, Heat, Moisture, and Momentum: Approach and Application to ARM Measurements, J. Atmos. Sci., 54, 1503-1524, 1997.

Zhuang, Y., Fu, R., Marengo, J. A., and Wang, H.: Seasonal variation of shallow-to-deep convection transition and its link to the environmental conditions over the Central Amazon, J. Geophys. Res. Atmos., 122, https://doi.org/10.1002/2016JD025993, 2017. 